\title{
Effects of Various Fuels on Combustion and Emission Characteristics of a Four-Stroke Dual-Fuel Marine Engine
}

\author{
Van Chien Pham ${ }^{1}$, , Beom-Seok Rho ${ }^{2}$, Jun-Soo Kim ${ }^{2}$, Won-Ju Lee ${ }^{3,4, * \mathbb{C}}$ and Jae-Hyuk Choi ${ }^{3, *}$ \\ 1 Marine Engineering Department, Graduate School of Korea Maritime and Ocean University, 727, Taejong-ro, \\ Busan 49112, Korea; phamvanchien.kmou@gmail.com \\ 2 Korea Institute of Maritime and Fisheries Technology, 367, Haeyang-ro, Busan 49111, Korea; \\ bsro@seaman.or.kr (B.-S.R.); jskim@seaman.or.kr (J.-S.K.) \\ 3 Division of Marine System Engineering, Korea Maritime and Ocean University, 727, Taejong-ro, \\ Busan 49112, Korea \\ 4 Interdisciplinary Major of Maritime AI Convergence, Korea Maritime and Ocean University, 727, Taejong-ro, \\ Busan 49112, Korea \\ * Correspondence: skywonju@kmou.ac.kr (W.-J.L.); choi_jh@kmou.ac.kr (J.-H.C.); \\ Tel.: +82-51-410-4262 (W.-J.L.); +82-51-410-4257 (J.-H.C.)
}

Citation: Pham, V.C.; Rho, B.-S.; Kim, J.-S.; Lee, W.-J.; Choi, J.-H. Effects of Various Fuels on Combustion and Emission Characteristics of a Four-Stroke Dual-Fuel Marine Engine. J. Mar. Sci. Eng. 2021, 9, 1072. https://doi.org/10.3390/jmse9101072

Academic Editor: Tie Li

Received: 23 July 2021

Accepted: 20 August 2021

Published: 1 October 2021

Publisher's Note: MDPI stays neutral with regard to jurisdictional claims in published maps and institutional affiliations.

Copyright: (c) 2021 by the authors Licensee MDPI, Basel, Switzerland. This article is an open access article distributed under the terms and conditions of the Creative Commons Attribution (CC BY) license (https:// creativecommons.org/licenses/by/ $4.0 /)$
Abstract: A numerical study was carried out to investigate the effects of methane $\left(\mathrm{CH}_{4}\right)$, ethane $\left(\mathrm{C}_{2} \mathrm{H}_{6}\right)$, propane $\left(\mathrm{C}_{3} \mathrm{H}_{8}\right)$, butane $\left(\mathrm{C}_{4} \mathrm{H}_{10}\right)$, and dimethyl ether (DME) on the combustion and emission characteristics of a four-stroke gas-diesel dual-fuel (DF) marine engine at full load. Three-dimensional simulations of the combustion process and emission formation inside the engine cylinder in the diesel and DF modes were performed using the AVL FIRE R2018a simulation software to analyze the incylinder pressure, temperature, and emission characteristics. The simulation results agreed well with the measured values reported in the engine shop test technical data. The simulation results showed reductions in the in-cylinder peak pressure and temperatures, as well as the emission formations, in the DF modes in comparison to the diesel mode. The DF mode could significantly reduce nitric oxide (NO) emissions (up to $96.225 \%$ ) of DME compared to the diesel mode. Meanwhile, $\mathrm{C}_{3} \mathrm{H}_{8}$ and $\mathrm{CH}_{4}$ fuels effectively reduced the soot (up to $82.78 \%$ ) and carbon dioxide $\left(\mathrm{CO}_{2}\right)$ emissions (by 21.33\%), respectively, compared to the diesel mode. However, the results also showed longer ignition delay times of the combustion processes when the engine operated in the DF mode, particularly in the DME-diesel mode. The combustion and emission characteristics of the engine were also analyzed when varying the injection timing; the results showed that applying the injection timing adjustment method could further address NO emission problems but led to a decrease in the engine power. Therefore, it is necessary to consider the benefits and disadvantages of adopting the injection timing adjustment strategy to address certain engine emission problems. This study successfully analyzed the benefits of using various gas fuels as alternative fuels and the injection timing adjustment method in DF marine engines to meet the International Maritime Organization (IMO) emission regulations without the use of any emission after-treatment devices.

Keywords: methane $\left(\mathrm{CH}_{4}\right)$; dimethyl ether (DME); dual-fuel (DF) engine; combustion; emission; start of injection (SOI)

\section{Introduction}

Emissions from ships that contain toxic pollutants negatively affect both human health and the environment [1-3]. Because of the increasing environmental hazards of marine engine exhaust emissions, and the International Maritime Organization (IMO) emission regulations are becoming increasingly strict, applying emission reduction solutions on new-building and existing ships to meet the emission regulations is mandatory [4-6]. Theoretically, engine exhaust gas emission reduction approaches are divided into three categories, including (1) pre-treatment; (2) internal treatment; and (3) post-treatment [7]. 
In pre-treatment approach, fuels, the main factor that affect the engine's combustion and emission characteristics are substituted or handled prior to supply to engines. Regarding substitute fuels, various gas fuels are currently being increasingly employed in marine engines to reduce engine exhaust gas emissions. Liquefied natural gas (LNG), ethane $\left(\mathrm{C}_{2} \mathrm{H}_{6}\right)$, liquefied petroleum gas (LPG) [8], butane $\left(\mathrm{C}_{4} \mathrm{H}_{10}\right)$, dimethyl ether (DME), or fuel oxygenates [9], etc. have been proven to be suitable diesel alternatives in diesel engines to reduce exhaust emissions while maintaining engine power [4,10-27]. Another way to pre-treat fuels is emulsifying liquid fuels with water to create emulsified fuels. Water in emulsified fuels will get the heat of combustion gas inside the engine cylinder to evaporate, resulting in a reduction in the in-cylinder temperature peak and thus NO emission [7].

In the internal treatment approach, the combustion of the fuel inside the engine cylinder will be modified towards the goal of achieving lower exhaust gas emissions. Using innovative fuel injection systems [28,29], lean or rich combustions [30], pre-chamber type combustion, innovative combustion bowl feature [31], etc. are examples of this method. In addition, the method of adding water to the engine combustion chamber to reduce the peak temperature in the cylinder or modifying the engine working cycle (exhaust gas recirculation-EGR is an example [32]) is also an effective way to reduce emissions. They are also being effectively used in the marine industry today.

In a post-treatment approach, it is necessary to equip exhaust gas after-treatment devices to treat the exhaust gas after it has left the engine. Using a selective catalytic reduction (SCR) system for NOx reduction is an example of this method [7]. These methods do not require modifications on fuels or existing engines, but exhaust gas after-treatment de-vices are mandatory. This results in an increase in additional costs and makes the engine room more cramped.

Focusing on the pre-treatment approach, the global demand for cleaner alternative fuels has become more prominent in today's shipping industry. To meet the IMO regulations on marine emissions, Korea has developed a plan to build and develop an environmentally eco-friendly fleet before 2030. This scheme will be applied to both coastal and oceangoing ships. For coastal vessels, the goal is to commercialize vessels using mixed fuels. Specifically, from 2021 to 2023, the plan is to commercialize liquefied petroleum gas (LPG) propulsion systems for small- and medium-sized ships. Almost simultaneously, from the middle of 2021 to 2024, the development and commercialization of mixed-fuel ship technology will begin. For ocean-going ships, from 2020 to 2023, the plan is to develop an alternative fuel injection system with a low flash point. From 2022 to 2025, smart engines will be developed using mixed fuels. From 2023 to 2027, modules will be developed to supply mixed fuels for engines. At the same time, from 2022 to 2027, the plan is to develop a system to evaluate the safety and quality of mixed fuels as well as bunkering technologies for ships using mixed-fuel propulsion systems. In addition, the plan is to develop turbine combination-cycle technology using hydrogen gas mixtures. The ultimate goal is to successfully develop mixed-fuel ship technology by 2030. Therefore, this study focuses on the combustion and emission characteristics of numerous alternative fuels that could be applied to environmentally eco-friendly ships in the near future.

Currently, various gas fuels are being increasingly employed in marine engines as alternative fuels to reduce engine exhaust gas emissions. Methane $\left(\mathrm{CH}_{4}\right)$, ethane $\left(\mathrm{C}_{2} \mathrm{H}_{6}\right)$, propane $\left(\mathrm{C}_{3} \mathrm{H}_{8}\right)$, butane $\left(\mathrm{C}_{4} \mathrm{H}_{10}\right)$, and dimethyl ether (DME) have been proven to be suitable diesel alternatives in diesel engines to reduce exhaust emissions while maintaining engine power. However, studies on their effects in comparison with actual ship data are extremely limited. Therefore, this study provides useful data for selecting fuels for future dual-fuel (DF) engines of eco-friendly ships.

Methane - the main component of natural gas (NG) - is a clean energy source that reduces marine engine exhaust emissions to meet the increasingly stricter IMO emission regulations $[10,11]$. Methane is known as the simplest and cleanest hydrocarbon fuel and produces less carbon-based emissions such as $\mathrm{CO}, \mathrm{CO}_{2}$, and soot than diesel oil when burning [4]. 
Ethane also was proposed as a clean transportation fuel. Yang et al. presented in [12] that ethane is a good transportation fuel due to its suitable physical and chemical properties for the combustion inside engine cylinders. However, extremely rare studies have focused on the emission performance of engines using ethane as fuel. In [13], the authors showed that the exhaust emissions from spark-ignited engines using ethane or methane as fuel were the same. Compared with gasoline engines, ethane gas engines typically produce only slightly fewer NOx emissions, but volatile organic compounds and particulate matter (PM) are significantly reduced. Because ethane, methane, and propane have nearly identical properties, one would reasonably expect that they would have the same emission performance [12].

Propane is also a suitable alternative for diesel oil. It occupies about $92 \%$ of LPG, while the $8 \%$ remaining is butane [14]. In comparison to most other oil products and alternative fuels, LPG has a higher energy density and cleaner combustion characteristics. The combustion of LPG produces lower $\mathrm{CO}_{2}$ emissions than oil-based fuels because of its lower carbon to hydrogen ratio. For two-stroke diesel engines, using LPG instead of heavy fuel oil (HFO) could help reduce the NOx emissions by 10-20\%. Meanwhile, using LPG for four-stroke Otto-cycle engines, the NOx emission could be expected to be reduced more significantly and might reduce to below the Tier III NOx regulations. Additionally, using LPG to a large degree might help significantly reduce PM and black carbon emissions similar to using LNG [15].

Butane has been also considered as a clean alternative fuel. Numerous researchers have focused on n-butane as a clean alternative fuel, which generally is liquefied to be injected into engine cylinders in dual-fuel technology. Studies in [16-19] have shown that n-butane could completely substitute fuels for diesel oil because n-butane has the same thermos-physical characteristics as diesel oil. This is an important factor of alternative fuels for dual-fuel diesel engines. Particularly, it would be a very suitable alternative fuel because of its high combustion efficiency and low emission characteristics when applying the twostage auto-ignition process (i.e., low heat release stage, LTR, and high heat release stage, HTR) in dual-fuel engines [20]. In fact, among the paraffin hydrocarbon family, n-butane has the lowest carbon number and can be interchanged well with higher hydrocarbons (diesel oil for instance) in combustion technology. It has also been shown to significantly reduce $\mathrm{CO}$ and $\mathrm{PM}$ emissions in the exhaust gas [18]. In addition, the combustion process of n-butane has fast chemical kinetics due to its small carbon number. These kinetics will aid in speeding-up the auto-ignition process and improving the combustion efficiency and emission performance $[21,22]$.

Dimethyl ether $\left(\mathrm{CH}_{3} \mathrm{OCH}_{3}\right)$ is a clean-burning, high-density liquid fuel and could be used as a direct alternative for diesel oil in power generation, transportation, heating, marine applications, and a wide variety of other applications. For the last 20 years, DME has been a known substitute for diesel because it is a clean fuel that produces low amounts of soot $[23,24]$. Unlike compressed natural gas (CNG) or LNG, DME can also be used in compression engines, which substantially affects the potential applications of this fuel. It is gaseous under ambient conditions and requires a pressure of approximately 5 bar to remain in the liquid state. However, it does not require cryogenic storage and can also be used along with spark ignition, diesel, turbine, or fuel-cell engines [25].

In addition, apart from DME, all the above gas fuels have higher lower calorific values (LCVs) than those of diesel; therefore, to maintain a certain engine output, the required fuel amount might be reduced if these gas fuels are used instead of diesel. This further results in a reduction in the amount of exhaust emissions generated inside the engine cylinder when gases are used as alternative fuels for diesel oil [26]. However, because gas fuels have high ignition temperatures (low cetane numbers), igniting them by direct compression is very difficult. Therefore, an external energy source, such as a spark plug or pilot diesel oil, is required to ignite gas fuels [27].

Conventional compression ignition (CI) diesel engines are widely used in modern society, however, they are also recognized as responsible for the majority of harmful emis- 
sions released into the environment such as particulate matter (PM) and nitrogen oxides (NOx). Furthermore, fossil fuel combustion releases carbon dioxide $\left(\mathrm{CO}_{2}\right)$ emission, a strong greenhouse gas (GHG) emissions [33]. The DF concept is a low-temperature combustion technology which enables the utilization of gas fuels in existing diesel engines. In such engines, a small amount of pilot fuel, normally diesel, is directly injected into the engine combustion chamber to ignite the port-fuel injected premixed gas-air mixture [34-36]. Diesel CI engines require highly reactive fuels that auto-ignite under high pressure and temperature conditions; thus, only a limited number of fuels can be used in CI engines. DF engines provide a way to use low-reactive fuels because they can use a pilot highly reactive fuel to produce ignition. By using diesel oil as a pilot fuel, DF engines enable the use of low reactive gas fuels as primary fuel instead of diesel oil, as in conventional diesel CI engines. This type of engine is the so-called gas-diesel DF engine. Additionally, dual-fuel concepts have also been investigated to reduce engine emissions. Conventional diesel combustion is diffusion-controlled and is typically accompanied by high nitrogen oxide (NOx) and PM emissions [37]. NOx emissions are caused by high in-cylinder temperature conditions which promote the combination of nitrogen (carried in with the fresh air) with excess oxygen [38]. Meanwhile, PM or soot is produced in fuel-rich regions when hydrocarbon species agglomerate [38,39]. As such, high local equivalence ratios can lead to soot formation and high local temperatures can lead to NOx formation. To avoid these problematic regions, many studies have attempted to operate dual-fuel engines in conditions that promote the premixing of the fuel and air and/or achieve in-cylinder stratification to reach high efficiencies and low emissions. By enabling more premixed combustion, rich regions where PM would be produced can be nearly eliminated and shorter combustion durations are achieved, which reduces local temperatures and thereby, NOx emissions [40-46]. Shipping and power generation industries have already adopted gas-operated DF engines, such as NG-diesel DF engines. These provide a high thermal efficiency compared to baseline diesel engines at high loads. In addition, they produce lower amounts of NOx and PM under lean conditions [47].

In summary, numerous studies were conducted to further develop the ICEs and they were mainly oriented to the application of innovative alternative combustion concepts in combination with the use of alternative fuels. The main concerns are engine efficiency and pollutants, especially reducing carbon dioxide $\left(\mathrm{CO}_{2}\right)$ while improving the NOx-PM trade-off compared to conventional diesel combustion (CDC). This has been also confirmed by Belgiorno et al. in their publication in Fuel in 2018 [48].

The main objective of this study was to analyze the combustion process and emission characteristics of an actual four-stroke gas-diesel DF marine engine. In particular, diesel is used as the pilot fuel, whereas gases are used as the primary fuel in DF modes. Various gas fuels (methane, ethane, propane, butane, and DME) have been used as the primary fuel for investigating their effects on the combustion and emission characteristics of the engine, with the aim of providing a basic understanding for selecting fuels for future DF engines of eco-friendly ships. The synergistic effects of these gaseous fuels when mixed together as in NG, LPG, etc. or mixed with carbon-free attractive fuels (hydrogen- $\mathrm{H}_{2}$, ammonia- $\mathrm{NH}_{3}$, etc.) on combustion and emissions characteristics of the gas-diesel DF engine will be the development of this study in our future works.

The AVL FIRE R2018a simulation software [49] was used to perform 3D simulations to calculate the combustion process and emission formations inside the engine cylinder. Two operating modes of the engine were simulated - the diesel mode (running the engine with diesel oil only) and the DF mode (the engine uses gas as the primary fuel and diesel oil as the pilot fuel) - to analyze the effects of various gas fuels on the in-cylinder pressure, temperature, and emission characteristics. The simulation results were then verified by comparing them using the engine shop test data provided by the engine manufacturer. The research results showed that utilizing the DF combustion concept in combination with the use of the researched alternative gas fuels could give a positive impact on emission 
performances (NOx-soot trade-offs) and $\mathrm{CO}_{2}(\mathrm{GHG})$ without any negative effect on engine power when applying to large marine DF engines.

\section{Numerical Setup}

\subsection{Engine Specifications and Fuel Properties}

The object of this research was a four-stroke gas-diesel DF marine engine. The effects of various gases when used as the primary fuel on the engine's in-cylinder pressure, temperature, and emission characteristics in the DF modes compared to those in the diesel mode were analyzed by simulating the combustion process and emission formations occurring in the engine cylinder. A schematic diagram of the simulated engine is shown in Figure 1. The piston surface had a $\omega$-type shape. The pilot fuel nozzle had 12 identical holes with an injection angle of $155^{\circ}$. Specifications of the simulated engine can be found in our previous publication [50].

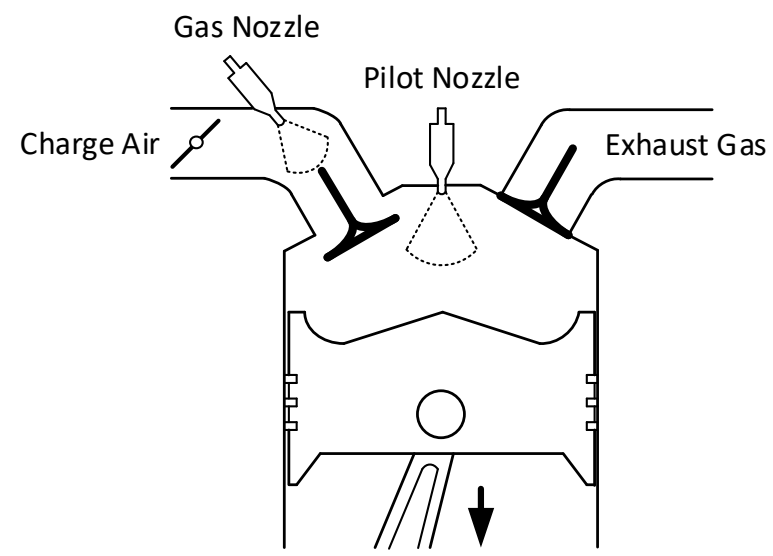

Figure 1. Schematic of the simulated engine.

The engine can be operated in two operating modes: the diesel mode and the DF mode. In the diesel mode, the engine uses only diesel, as in conventional CI diesel engines. Meanwhile, in the DF mode, the engine uses gas fuels as the primary fuel while diesel oil plays a role as the pilot fuel. In the DF modes, gas is injected into the intake port through the gas injection nozzle to mix with the charge air to form a premixed mixture prior to being supplied into the engine cylinder, whereas the diesel pilot fuel is directly injected into the engine cylinder by a pilot fuel nozzle mounted in the center of the engine cylinder cover.

In this study, $\mathrm{C}_{13} \mathrm{H}_{23}$ was used to represent diesel oil and acted as the pilot fuel, whereas the gas fuels were methane, ethane, propane, butane, and DME, and were the primary fuel in DF modes. All of the properties of the fuels are temperature-dependence functions. The main properties of diesel and gas fuels at the pressure of 1 at and temperature of $25^{\circ} \mathrm{C}$ are shown in Table 1.

\subsection{CFD Simulation Models}

The AVL FIRE R2018a simulation software with its state-of-the-art models has been proven to be suitable for simulating combustion and emission formation inside gasoline, diesel, and DF engines with high accuracy [49]. In this study, the AVL FIRE ESE Diesel platform built by the AVL FIRE R2018a software was used to simulate the engine's working process from the time when the intake valve is closed (IVC) to the time the exhaust valve is opened (EVO).

The simulation process included three steps: (1) pre-processing, (2) processing, and (3) post-processing. The first step included declaring general engine parameters, building computational domains, creating movable computational meshes, and setting up the simulation parameters. The solutions were calculated in the second step. In the third step, the simulation results were analyzed and reported. After obtaining the simulation 
results, the simulation results and measured results were compared for the validation of the simulation models. This process was repeated until the simulation and measured results matched. Figure 2 shows the workflow of the study.

Table 1. Main properties of fuels.

\begin{tabular}{|c|c|c|c|c|c|c|}
\hline \multicolumn{7}{|c|}{$\begin{array}{l}\text { Measurement Conditions: } \mathrm{P}=1 \mathrm{at} ; \mathrm{T}=25{ }^{\circ} \mathrm{C} \\
\text { Source: AVL FIRE Database }\end{array}$} \\
\hline \multirow{2}{*}{$\begin{array}{c}\text { Properties } \\
\text { Working Mode }\end{array}$} & \multicolumn{6}{|c|}{ Fuel } \\
\hline & Diesel & \multicolumn{5}{|c|}{ Dual-Fuel [Pilot: Diesel; Primary: Gas] } \\
\hline Chemical Name & - & Methane & Ethane & Propane & Butane & DME \\
\hline Formula & $\mathrm{C}_{13} \mathrm{H}_{23}$ & $\mathrm{CH}_{4}$ & $\mathrm{C}_{2} \mathrm{H}_{6}$ & $\mathrm{C}_{3} \mathrm{H}_{8}$ & $\mathrm{C}_{4} \mathrm{H}_{10}$ & $\mathrm{CH}_{3} \mathrm{OCH}_{3}$ \\
\hline Density $\left[\mathrm{kg} / \mathrm{m}^{3}\right]$ & 786 & 0.6679 & 1.263 & 1.91 & 2.46 & 1.617 \\
\hline $\mathrm{LCV}[\mathrm{MJ} / \mathrm{kg}]$ & 42.343 & 50 & 46.533 & 46.3 & 44.9 & 28.4 \\
\hline$C_{p}[\mathrm{~J} / \mathrm{kg} \cdot \mathrm{K}]$ & 2090 & 2190.5 & 1741.66 & 1668 & 1692 & 1859.39 \\
\hline$C_{p, \text { mix }}[\mathrm{J} / \mathrm{kg} \cdot \mathrm{K}]$ & 1015.37 & 1006.3 & 1006.69 & 1006.85 & 1006.93 & 1011.31 \\
\hline$k[\mathrm{~W} / \mathrm{m} \cdot \mathrm{K}]$ & 0.149 & 0.0332 & 0.0267 & 0.0177 & 0.0159 & - \\
\hline$\mu[\mathrm{kg} / \mathrm{m} \cdot \mathrm{s}]$ & 0.0024 & $1.087 \times 10^{-5}$ & $9.29 \times 10^{-6}$ & $7.95 \times 10^{-6}$ & $7 \times 10^{-6}$ & - \\
\hline LCV: & \multicolumn{2}{|c|}{ Lower Calorific Value } & $k:$ & \multicolumn{3}{|c|}{ Thermal Conductivity } \\
\hline$C_{p, \text { mix }}:$ & \multicolumn{6}{|c|}{ Air-Fuel mixture's Specific Heat Capacity } \\
\hline$C_{p}:$ & Specific & Capacity & $\mu:$ & \multicolumn{3}{|c|}{ Dynamic Viscosity } \\
\hline
\end{tabular}

To simulate the turbulence of the fluid flow inside the engine cylinder, the k-zeta-f turbulence model was used. This model was developed from the $\mathrm{k}-\varepsilon$ two-equation model to become a four-equation model and had higher precision as well as better stability than the k- $\varepsilon$ two-equation turbulence model [51]. In the CFD method, the mixing and transports of chemical species in combustion problems will be modeled by solving equations of conservations describing diffusion, convection phenomenon, reaction sources, and concentrations for each component species. Therefore, species transport models must be used in conjunction with combustion models to model combustion problems. In this study, the species transport model provided by AVL FIRE in conjunction with the extended coherent flame model (ECFM) [52,53] was used to simulate the combustion process occurring inside the engine cylinder. Among the combustion models provided by AVL FIRE, the ECFM, which contains all features and improvements of the coherent flame model, has been proven to be suitable for simulating combustion inside gasoline, diesel, and DF engines with high accuracy and has been successfully employed in many previous studies [50,54-57]. Therefore, it was chosen to simulate engine combustion in this study. The species transport model and the ECFM are presented in detail in Appendix A and B, respectively, in our previous research [50]. To simulate the pilot fuel direct injection, a diesel nozzle flow sub-model $[53,58]$ was used. This model offers a simple method to correct the injection velocities and initial droplet diameters due to cavitation. The breaking up and evaporation phenomena of fuel droplets were simulated using WAVE [53,58]- the model that was developed into the Kelvin-Helmholtz (KH) instability [59]—and the multi-component sub-model [53,58], respectively. The diesel ignited gas engine model [53] was used to simulate the self-ignition phenomenon of diesel pilot fuel that occurs in a diesel-ignited DF engine.

The extended Zeldovich mechanism [53,60], which comprised of seven species and three reactions, has been used to model NO formation inside the engine cylinder and has been proven to be able to highly accurately predict thermal $\mathrm{NO}$ formation inside engine cylinders over a wide range of equivalence ratios in many studies [36,61-63]. The kinetic soot mechanism $[53,60]$ was used to simulate the soot formation owing to the combustion process. The extended Zeldovich model and kinetic soot mechanism have been presented 
in detail in Appendix C and D, respectively, in our previous research [50]. The interaction between the fuel droplets and walls was simulated using the Walljet1 sub-model [53,58], which is developed from the spray/wall impingement model built by Naber and Reitz [64]. Other CFD models can be found in the literature [53,58,60]. Table 2 summarizes the numerical models used in this study.

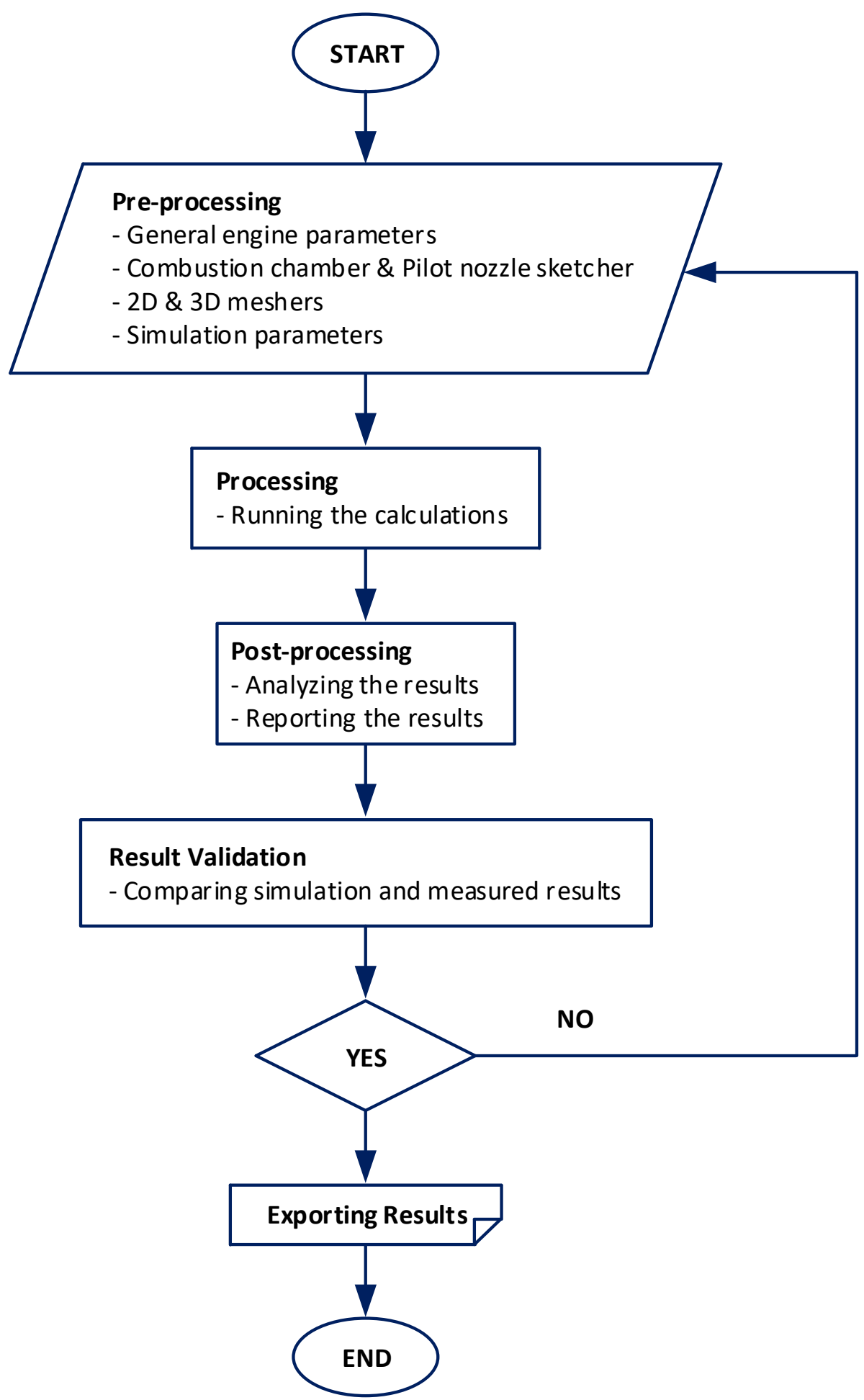

Figure 2. The workflow of the study. 
Table 2. Summary of the numerical models.

\begin{tabular}{|c|c|c|}
\hline Model & \multicolumn{2}{|c|}{ Description } \\
\hline Turbulence & \multicolumn{2}{|c|}{ k-zeta-f } \\
\hline \multirow{2}{*}{ Combustion } & \multicolumn{2}{|c|}{ Standard Species Transport Model } \\
\hline & \multicolumn{2}{|c|}{ Extended Coherent Flame Model_ECFM } \\
\hline \multirow{2}{*}{ Emission } & $\mathrm{NO}$ & Extended Zeldovich \\
\hline & Soot & Kinetic Soot formation \\
\hline Ignition & \multicolumn{2}{|c|}{$\begin{array}{c}\text { Auto-Ignition Model (Diesel Mode) } \\
\text { Diesel Ignition Gas Engine (Dual-Fuel Mode) }\end{array}$} \\
\hline \multirow{3}{*}{ Atomization } & Breakup & WAVE \\
\hline & Evaporation & $\begin{array}{l}\text { Dukowicz Model (Diesel Mode) } \\
\text { Multi-component (Dual-Fuel Mode) }\end{array}$ \\
\hline & Droplet-wall interaction & Walljet1 \\
\hline
\end{tabular}

\subsection{Computational Mesh, Boundary, and Initial Conditions}

The AVL FIRE ESE-Diesel platform was used to build a 3D engine combustion chamber geometry and then create a computational mesh for the CFD analysis. Owing to the axial symmetry of the engine combustion chamber, the fuel nozzle of the engine had 12 identical holes, and to reduce the calculation time, only $1 / 12$ of the entire 3D computational mesh of the combustion chamber was generated. The calculation was started from the IVC to the EVC and performed in series using a twelve-core processor and took approximately $36 \mathrm{~h}$ of CPU time. Figure 3 shows a schematic diagram of the working cycle of the engine. Figure 3 shows the schematic of the engine working cycle in this study. Figures 4 and 5 respectively show the $2 \mathrm{D}$ combustion chamber geometry and $1 / 12$ of the entire $3 \mathrm{D}$ computational mesh of the combustion chamber at 40 crank angle degrees (CAD) after the top dead center (ATDC).

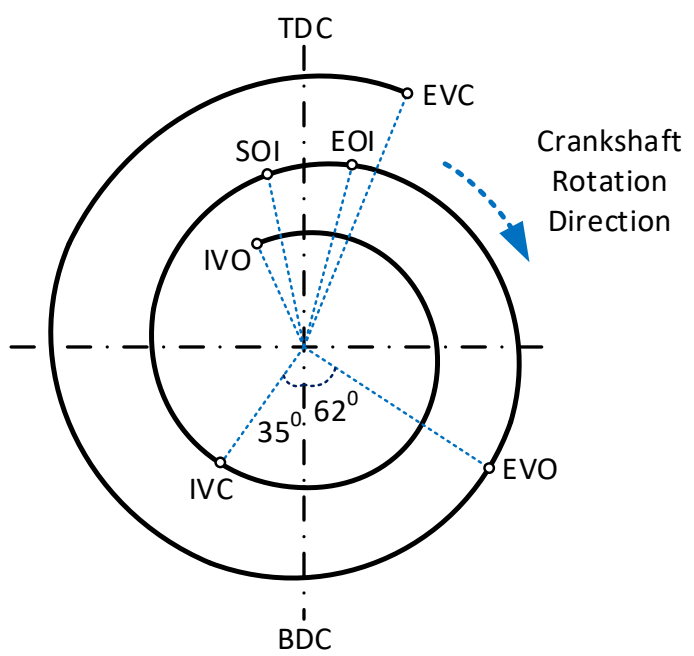

Figure 3. Schematic of the engine working cycle (TDC: Top dead center, BDC: Bottom dead center; IVC: Intake valve closes; EVO: Exhaust valve opens; SOI: Start of injection; EOI: End of injection).

The boundary conditions and initial conditions were chosen from the technical report of the actual engine provided by the engine manufacturer and presented in detail in our previous research [50]. Table 3 lists the BCs and initial conditions for the numerical simulation cases. 


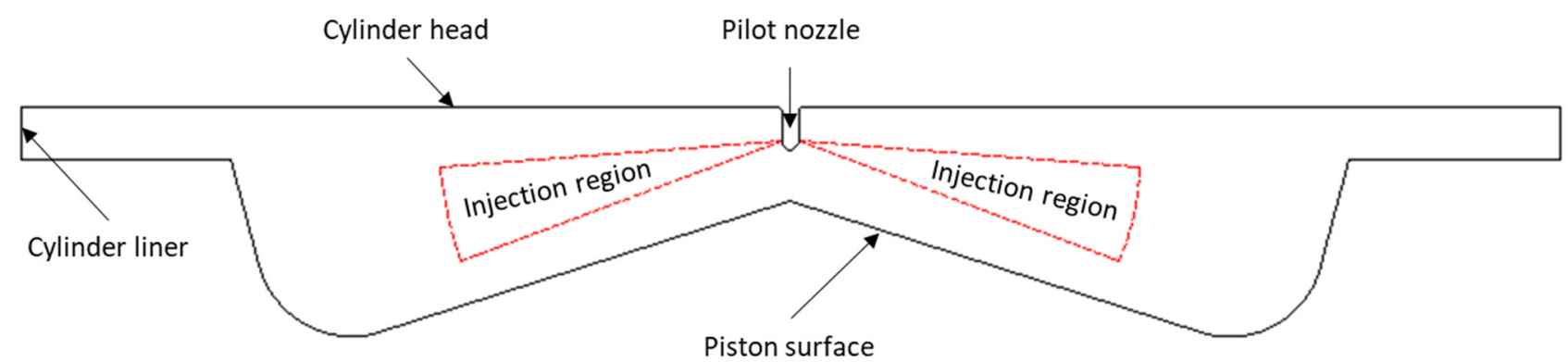

Figure 4. Engine combustion chamber geometry.

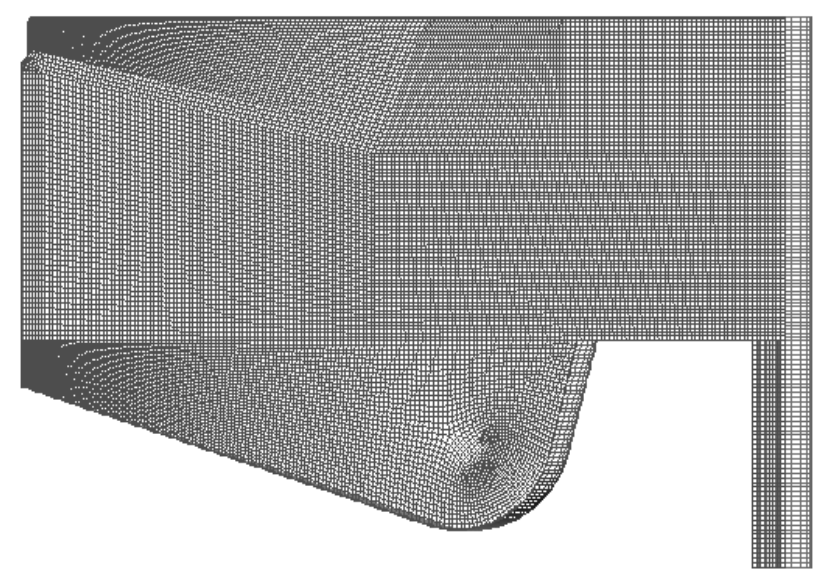

Figure 5. One-twelfth portion of the entire 3D computational mesh of the combustion chamber at 40 CAD ATDC.

Table 3. Boundary conditions and initial conditions for the numerical simulation cases.

\begin{tabular}{cc}
\hline Boundary Conditions & Boundary Type/Specific Condition \\
\hline Piston & Mesh movement/Temp. $/ 570 \mathrm{~K}\left(297^{\circ} \mathrm{C}\right)$ \\
\hline Liner & Wall/Temp. $/ 470 \mathrm{~K}\left(197^{\circ} \mathrm{C}\right)$ \\
\hline Cylinder head & Wall/Temp. $/ 570 \mathrm{~K}\left(297^{\circ} \mathrm{C}\right)$ \\
\hline Segment cut & Periodic/Inlet/outlet \\
\hline Initial Conditions & Value \\
\hline Temperature at IVC & $320 \mathrm{~K}\left(47^{\circ} \mathrm{C}\right)$ \\
\hline Pressure at IVC & $0.35 \mathrm{MPa}$ \\
\hline IVC & $35 \mathrm{CAD}$ ABDC \\
\hline EVO & $62 \mathrm{CAD} \mathrm{BBDC}$ \\
\hline SOI & $12 \mathrm{CAD}$ BTDC \\
\hline Diesel injection duration & 7.5 milliseconds in the diesel mode \\
\hline
\end{tabular}

\subsection{Simulation Conditions}

In this study, numerous simulations of the combustion processes of an engine running in the diesel and DF modes at full load were simulated. In the diesel mode, the engine uses only diesel oil as a conventional CI diesel engine. In the DF modes, the engine uses gas as the primary fuel and diesel oil as the pilot fuel. In these modes, the primary gas fuel was injected into the intake port by a gas supplying unit during the suction stroke. Therefore, the gas fuel was mixed with the charged air to generate a homogeneous premixed mixture prior to being supplied to the cylinder. Meanwhile, diesel fuel (pilot fuel) was directly 
injected into the cylinder by a pilot fuel injector to supply an ignition source for igniting the pre-mixed gas-air mixture at the end of the compression process. All the other simulation conditions remained unchanged.

To keep the engine power unchanged, the amount of fuel supplied to the engine when running on different fuels had to be changed owing to the difference in the LCVs between the diesel and gas fuels. The fuel dosage in each running mode as well as the energy share of the diesel pilot fuel in the total energy of fuels generated inside the engine cylinder in the DF mode are listed in Table 4. The differences in the total fuel mass used in the different running modes are due to the differences in the LCVs among the various fuels used. The energy share of the diesel pilot fuel in the total energy of fuels generated inside the engine cylinder in the DF modes can be calculated using Equation (1).

$$
E_{f}^{\text {diesel }}=\frac{m \text { Diesel } \times \text { LCV of Diesel }}{(m \text { Diesel } \times L C V \text { of Diesel })+(m \text { Gas } \times L C V \text { of Gas })}
$$

where, $E_{f}^{\text {diesel }}$ is the energy fraction of diesel, and mDiesel and $m G$ as are the masses of diesel and gas fuel used for one cycle, respectively. LCV of Diesel and LCV of Gas are the lower calorific values of diesel and gas fuel, respectively.

Table 4. Fuel dosage and energy share of diesel pilot fuel in the total fuel dosage.

\begin{tabular}{ccccc}
\hline \multirow{2}{*}{ Working Mode } & \multicolumn{3}{c}{ Fuel Dosage } \\
\cline { 2 - 5 } & $\begin{array}{c}\text { Mass } \\
\text { (kg/cycle) }\end{array}$ & $\begin{array}{c}\text { Energy Share } \\
\mathbf{( \% )}\end{array}$ & $\begin{array}{c}\text { Mass } \\
\text { (kg/cycle) }\end{array}$ & $\begin{array}{c}\text { Energy Share } \\
(\mathbf{\%})\end{array}$ \\
\hline Diesel & 0.0020667 & 100 & 0 & 0 \\
\hline $\mathrm{CH}_{4} /$ Diesel & 0.0001 & 4.793 & 0.001682 & 95.207 \\
\hline $\mathrm{C}_{2} \mathrm{H}_{6} /$ Diesel & 0.0001 & 4.783 & 0.0019115 & 95.217 \\
\hline $\mathrm{C}_{3} \mathrm{H}_{8} /$ Diesel & 0.0001 & 4.65 & 0.0019753 & 95.35 \\
\hline $\mathrm{C}_{4} \mathrm{H}_{10} /$ Diesel & 0.0001 & 4.724 & 0.0020021 & 95.276 \\
\hline $\mathrm{DME} /$ Diesel & 0.0001 & 4.51 & 0.0032568 & 95.49 \\
\hline
\end{tabular}

The simulation results among all simulation cases were then compared to analyze the effects of various fuels on the in-cylinder temperature, pressure, and emission characteristics of the engine.

\subsection{Mesh Independence Analysis}

The accuracy of the final CFD results strongly depends on the mesh quality or, in another word, the mesh resolution. However, the mesh resolution also affects the calculation time. In general, finer meshes give better mesh qualities resulting in higher CFD result accuracies but also prolong the calculation time. Therefore, to ensure the accuracy of the final CFD results and the reasonableness of the calculation time, a mesh independence analysis was performed by performing three simulations with three mesh resolutions, including a coarse, medium, and fine mesh. By analyzing the mesh independence, it is possible to choose the appropriate mesh resolution at which the calculation still yields accurate CFD results but in a shorter time period. Table 5 lists the mesh properties and computation time of the three different mesh resolutions.

Figure 6 shows the final simulation CFD results when using the three mesh resolutions. As can be seen, the final CFD results did not depend on the resolution of the three meshes. Therefore, technically, all three mesh solutions can be used for calculations to obtain accurate and mesh-independent final results. However, mesh 2 was chosen for the simulations in this study because it took a reasonable time for the calculation process while 
providing mesh-independent calculation results and had an appropriate density for good contour analysis in the next steps.

Table 5. Mesh properties and calculation time.

\begin{tabular}{cccc}
\hline Mesh Resolutions & Mesh 1-Coarse & Mesh 2-Medium & Mesh 3-Fine \\
\hline Number of faces on the 2D mesh at the TDC & 12.949 faces & 17.715 faces & $39.307 \mathrm{faces}$ \\
Total number of cells of entire 3D mesh & $586.796 \mathrm{cells}$ & $882.620 \mathrm{cells}$ & $1.593 .732 \mathrm{cells}$ \\
Calculation time & $24 \mathrm{~h}$ & $36 \mathrm{~h}$ & $92 \mathrm{~h}$ \\
\hline
\end{tabular}
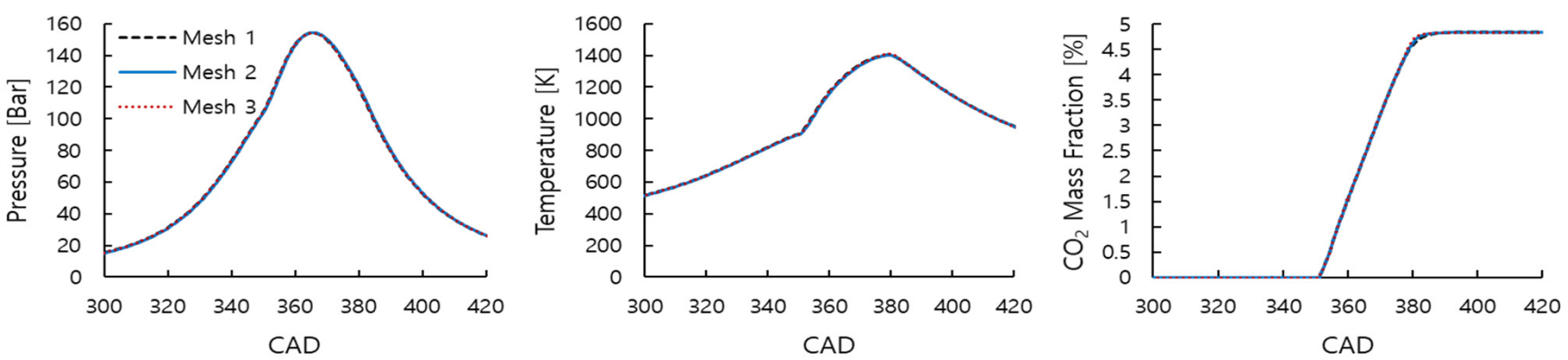

Figure 6. CFD results of the simulations using the three different mesh resolutions.

\subsection{CFD Simulation Model Validation}

After obtaining the convergence in calculating the solution, we plotted the energy balance to confirm the energy conservation. The energy balance plot showed that the energy balance at the end of the calculations $(\mathrm{CAD}=478)$ in all of the calculation cases was almost equal to zero, confirming that the calculations have gotten energy balances. The simulation results were then verified again by comparing them with the measured results reported in the engine shop test data provided by the engine manufacturer. The comparisons between the simulation and measurement results for the diesel and DF modes are shown in Figure 7. The engine shop test conditions and the tested results are listed in Table 6. The measured and simulated values used for CFD model validation were the in-cylinder peak pressure, the $\mathrm{NO}$ and $\mathrm{CO}_{2}$ emissions of the engine running at the full load with a speed of $720 \mathrm{rpm}$.
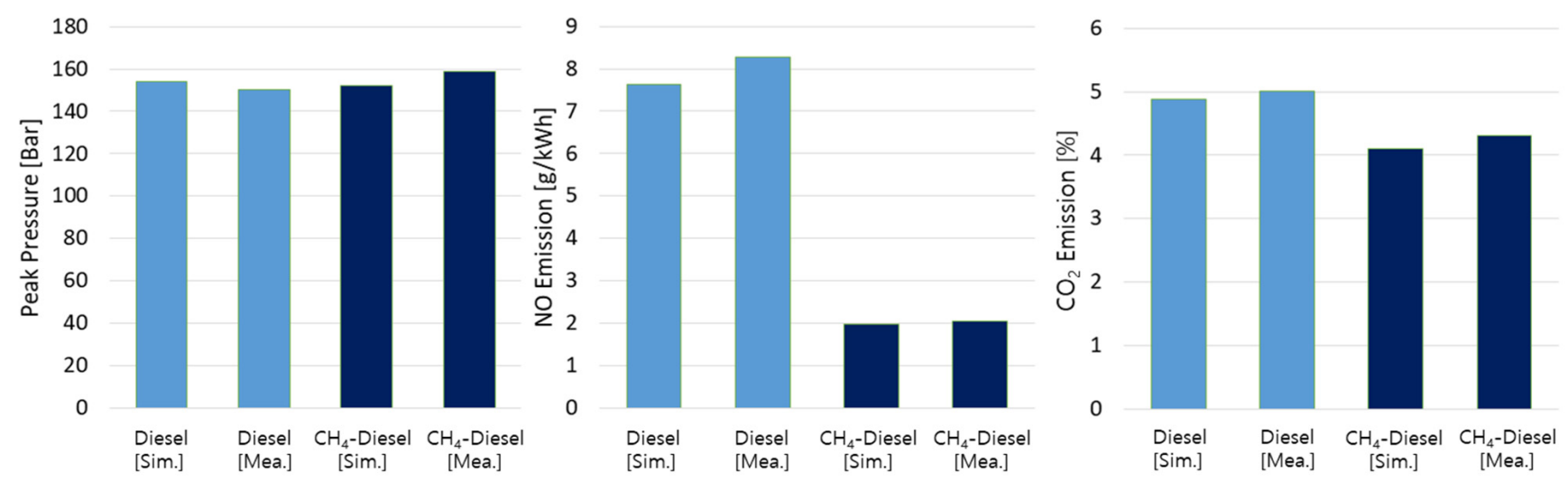

Figure 7. Comparisons of simulation results and shop test data.

From Figure 7, it is obvious that the simulation results and the shop test data are in good agreement. In the diesel mode, the deviation between the simulated and measured peak pressures was only $0.22 \%$, whereas the deviations between the simulated and measured $\mathrm{NO}$ and $\mathrm{CO}_{2}$ emissions were $7.7 \%$ and $2.7 \%$, respectively. Meanwhile, in the DF mode, the deviation between the simulated and measured peak pressures was only $4.43 \%$, 
and the deviations between the simulated and measured $\mathrm{NO}$ and $\mathrm{CO}_{2}$ emissions were $3.4 \%$ and $4.87 \%$, respectively. After validating the CFD simulation models, the validated models were applied to simulate the combustion and emission formations inside the engine cylinder for all gas fuels.

Table 6. Engine specifications and shop test conditions and results.

\begin{tabular}{|c|c|c|}
\hline \multicolumn{2}{|c|}{ Specifications } & Value \\
\hline \multicolumn{2}{|c|}{ Engine name } & $6 \mathrm{H} 35 \mathrm{DF}$ \\
\hline \multicolumn{2}{|c|}{ Rated power and speed } & 2880 kW@ 920 rpm \\
\hline \multicolumn{2}{|c|}{ IMEP } & 20 bar \\
\hline \multicolumn{2}{|c|}{ Max. cylinder pressure } & 154 bar \\
\hline \multicolumn{2}{|c|}{ Compression ratio } & 13.5 \\
\hline \multicolumn{2}{|c|}{ Injection angle } & 153 deg. \\
\hline \multicolumn{2}{|c|}{ Charge air pressure } & 5.16 bar \\
\hline \multicolumn{2}{|c|}{ Intake air temperature } & $299 \mathrm{~K}\left(26^{\circ} \mathrm{C}\right)$ \\
\hline \multicolumn{2}{|c|}{ Charge air temperature } & $320 \mathrm{k}\left(47^{\circ} \mathrm{C}\right)$ \\
\hline \multicolumn{2}{|c|}{ IVC } & 35 CAD ABDC \\
\hline \multicolumn{2}{|c|}{ EVO } & 62 CAD BBDC \\
\hline \multirow{2}{*}{ NO emission } & Diesel mode & $8.27 \mathrm{~g} / \mathrm{kWh}$ \\
\hline & DF mode & $2.05 \mathrm{~g} / \mathrm{kWh}$ \\
\hline \multirow{2}{*}{$\mathrm{CO}_{2}$ emission } & Diesel mode & $5.01 \%$ \\
\hline & DF mode & $4.31 \%$ \\
\hline
\end{tabular}

\section{Simulation Results}

To clearly illustrate the effects of various gas fuels on combustion and emission formations inside the engine cylinder, all the BCs and working conditions of the engine remained unchanged, except for the difference in the fuels to be used; that is, only diesel was used in the diesel mode and gas-diesel was used in the DF mode. In addition, for the purpose of studying the influence of the SOI timings on the combustion and emission formations of the engine, numerous simulations of the combustion by adjusting the SOI timing were performed. In this section, the in-cylinder pressure, temperature, and emissions in all simulation cases are presented and analyzed.

\subsection{In-Cylinder Fluid Flow Turbulence}

Typically, the mean turbulence kinetic energy (TKE) is used to analyze the turbulence intensity of the fluid flow inside the engine cylinder. TKE is the average kinetic energy in one unit of mass associated with eddies in turbulent flows in fluid dynamics. Physically, TKE is characterized by the fluctuations of the measured root-mean-square (RMS) velocities. According to the Reynolds and Navier-Stokes equations, the TKE can be calculated by turbulence models, which are built based on the closure method. In general, the TKE is defined as half the sum of the velocity component variances (square of standard deviations), as shown in Equation (2) [65].

$$
k=\frac{1}{2}\left(\overline{\left(u^{\prime}\right)^{2}}+\overline{\left(v^{\prime}\right)^{2}}+\overline{\left(\omega^{\prime}\right)^{2}}\right)
$$

In Equation (2), $k, u^{\prime}, v^{\prime}$, and $\omega^{\prime}$ denote the TKE and the turbulent part of the horizontal ( $x$ - and $y$-axis) and vertical ( $z$-axis) velocities of turbulence flows, respectively. TKE is proportional to the square of the turbulence velocity components. In other words, TKE 
intensity indicates the intensity of the turbulence of the fluid flow in the engine cylinder. Higher TKEs indicate higher turbulence intensities of fluid flows.

The mean TKEs of the fluid flow in the entire engine cylinder for all operating modes are shown in Figure 8. Comparing the diesel mode and DF modes, the maximum value of the TKE and the mean TKE during the combustion and expansion processes in the diesel mode are larger than those in the DF modes. This indicates that the turbulence velocity of the fluid flow in the engine cylinder in the diesel mode is higher than that in the DF mode. The reasons may be due to the differences in the rate as well as the duration of the heat release in the engine cylinder. As shown in Figure 9, the rate of heat release (RoHR) in the diesel mode was maintained at a high value for a shorter heat release duration compared to that in the DF modes. Because almost all heat was released in a shorter period, the turbulence velocity of the fluid flow in the engine cylinder and, thus, the TKE in the diesel mode was higher than that in the DF mode.

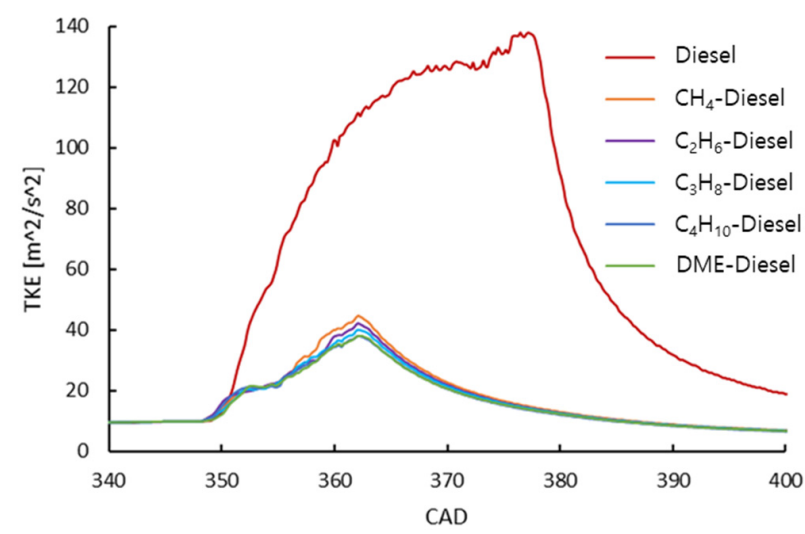

Figure 8. Mean TKEs of the fluid flow in the engine cylinder in all operating modes.

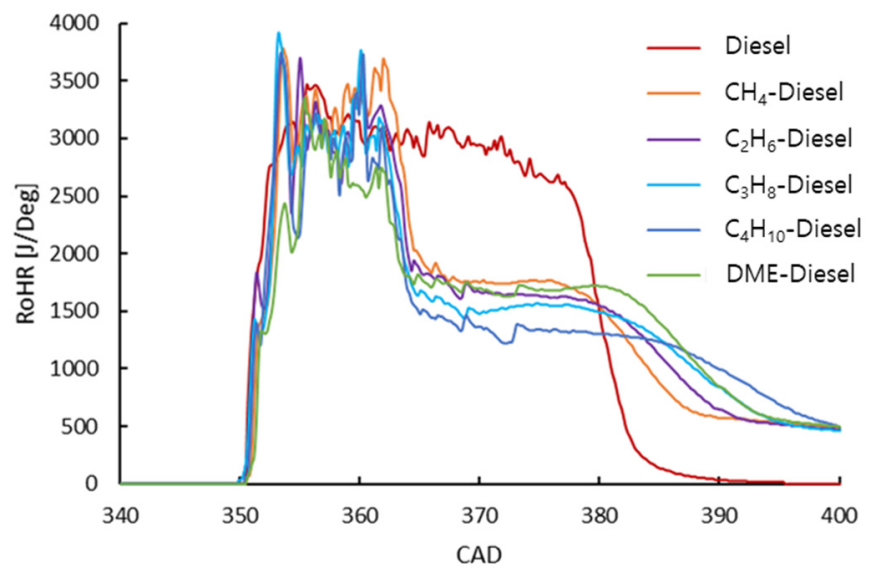

Figure 9. Rate of heat release diagrams.

Additionally, the turbulence intensity inside the engine cylinder is not only influenced by the RoHR but also by the physical factors, in this case, it is the velocity of the injected flow. As mentioned in Table 4, in the diesel mode, all of the fuels were directly injected into the engine cylinder, meanwhile, only a little amount of diesel pilot fuel (less than 5\%) was injected into the cylinder in the DF modes. Physically, with the same fuel nozzle hole cross-section area $\left(A\left[\mathrm{~m}^{2}\right]\right)$, the injected fuel velocity $(v[\mathrm{~m} / \mathrm{s}])$ will increase if the injected fuel mass flow rate $(Q[\mathrm{~kg} / \mathrm{s}])$ increase according to the following equation (for liquid (incompressible) flows):

$$
Q[\mathrm{~kg} / \mathrm{s}]=A\left[\mathrm{~m}^{2}\right] \times v[\mathrm{~m} / \mathrm{s}] \times \rho\left[\mathrm{kg} / \mathrm{m}^{3}\right]
$$


where $\rho\left[\mathrm{kg} / \mathrm{m}^{3}\right]$ is the density of the liquid.

An increase in the injected fuel velocity results in an increase in the penetration of the injected fuel helping the fuel droplets can touch more hot air for a better evaporation process and then better combustion quality at the start of combustion. These consequently increase the turbulence intensity (that is TKE) of the gas flow inside the engine cylinder.

Comparing the DF modes, the results showed that the maximum TKEs reduced in the following order: $\mathrm{CH}_{4}, \mathrm{C}_{2} \mathrm{H}_{6^{-}}, \mathrm{C}_{3} \mathrm{H}_{8^{-}}$, and $\mathrm{C}_{4} \mathrm{H}_{10}$-diesel DF modes. In contrast, they were almost the same in the $\mathrm{C}_{2} \mathrm{H}_{6}$ - and DME-diesel DF modes. This is because, as shown in Figure 9, except the heat release rates, which were almost the same in all combustion cases due to the dominance of the diesel (pilot) fuel premixed combustion in the first stage of combustion, the heat release rates in the second stage of combustion (premixed combustion of the gas-air mixture) of DF modes reduced in the order of $\mathrm{CH}_{4}^{-}, \mathrm{C}_{2} \mathrm{H}_{6}-\mathrm{C}_{3} \mathrm{H}_{8^{-}}$, and $\mathrm{C}_{4} \mathrm{H}_{10}$-diesel DF modes. This reduces the maximum TKEs according to the order of $\mathrm{CH}_{4}{ }^{-}$, $\mathrm{C}_{2} \mathrm{H}_{6^{-}}, \mathrm{C}_{3} \mathrm{H}_{8^{-}}$, and $\mathrm{C}_{4} \mathrm{H}_{10}$-diesel DF modes, as shown in Figure 9.

\subsection{In-Cylinder Pressure}

The simulated in-cylinder pressure diagrams for all the combustion cases are shown in Figure 10. The simulation results showed that the in-cylinder peak pressure was reduced by $1.7 \%, 3.4 \%, 4.76 \%, 5.7 \%$, and $8.8 \%$ in the $\mathrm{CH}_{4^{-}}, \mathrm{C}_{2} \mathrm{H}_{6^{-}}, \mathrm{C}_{3} \mathrm{H}_{8^{-}}, \mathrm{C}_{4} \mathrm{H}_{10^{-}}$, and DME-diesel DF modes, respectively.

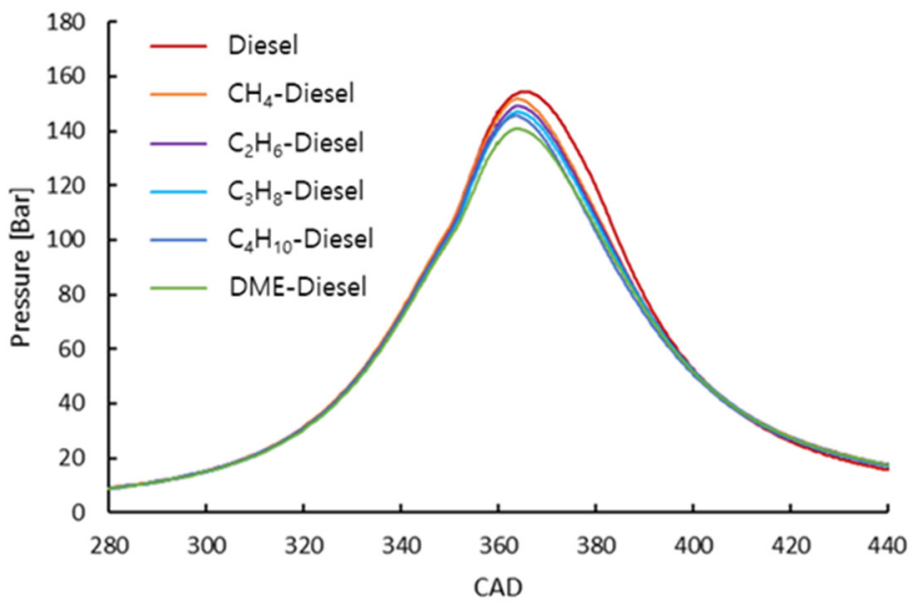

(a)

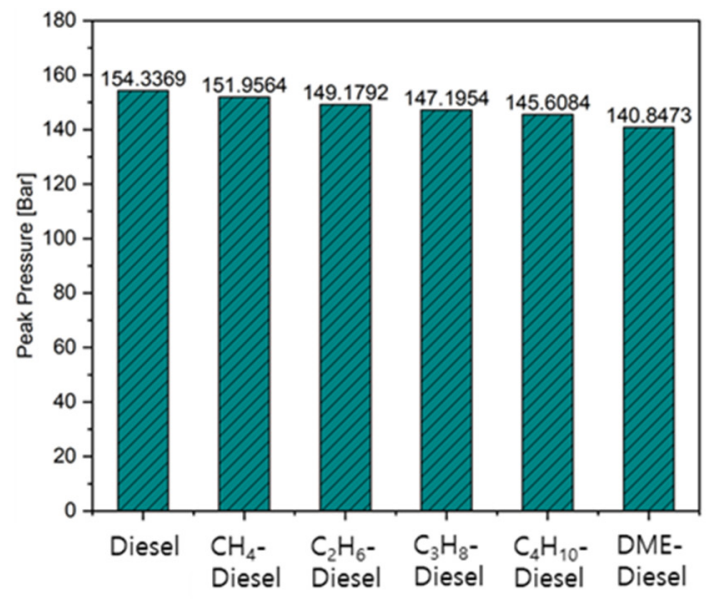

(b)

Figure 10. The mean in-cylinder pressure diagrams (a) and maximum in-cylinder pressure (b) in all operating modes.

The lower in-cylinder peak pressure in the DF modes is due to the lean premixed combustion characteristics and slower burning rate of DF combustion. The normal combustion process in a gas-port-injection-diesel DF engine typically occurs in three stages [66]. The first stage begins when the diesel pilot fuel is directly injected into the engine cylinder, which already contains a premixed mixture of gas and air. Because the diesel droplets need time to receive heat for heating and vaporization, the diesel will not ignite immediately but after a few moments, which is the ignition delay time. During the ignition delay time, the injected diesel droplets will mix with air in the cylinder, forming a pre-mixed (diesel-air) mixture. Therefore, this stage of combustion includes the premixed combustion of the diesel pilot fuel and a small portion of the port injection gas fuel. However, because gas fuels have a higher activation energy, resulting in a higher auto-ignition temperature, the combustion of premixed diesel is the main contributor. Additionally, almost all the diesel pilot fuel is completely burned in this stage of DF combustion, as shown in Figure 11. During this stage, rapid pressure and temperature rise occur because of the initiation of diesel combustion. In these DF modes, because the diesel fuel injected is much less than that in the diesel mode, the pressure rise rate $(d P / d \varphi)$, that is, the pressure rise value per 
CAD, in the case of DF combustion is lower than that in the diesel mode, as can be seen in Figure 10a. The second stage starts after the initial combustion of diesel and provides an ignition source. In this stage, the continuing injected diesel fuel will immediately ignite when injected into the cylinder; therefore, this stage involves diffusion combustion of the diesel pilot fuel along with the initiation and flame propagation of gas combustion due to the presence of the ignition source. During this stage, the combustion of the diesel pilot fuel is mixing-controlled, and the premixed gas flame propagates from the ignition kernels. The spatial visualization of combustion inside the engine cylinder in this combustion stage at some crank angle positions is presented in Section 3.6. Lastly, the diffusion combustion of the residual diesel pilot fuel and late combustion phase of the gas fuel, or in other words, most of the fuels remaining in the engine cylinder, will be burned in the third stage of combustion [67-70].

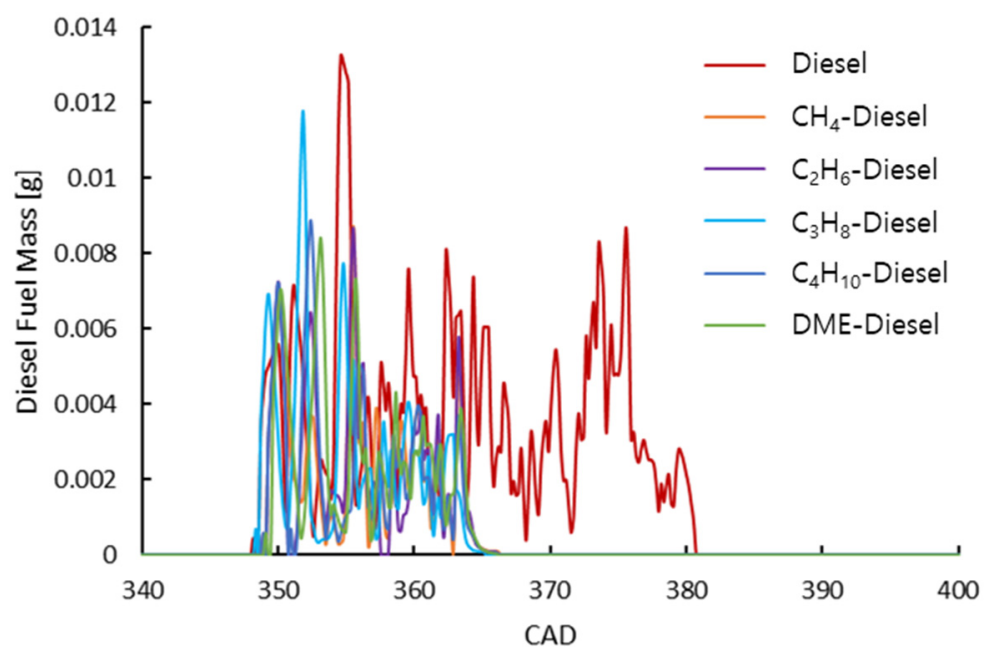

Figure 11. Liquid diesel mass remaining in the engine cylinder.

As widely known, RoHR plays a very important role in the in-cylinder pressure rise during the engine combustion process, so analyzing the in-cylinder pressure curve in conjunction with the RoHR traces will give a detailed sight into the thermodynamic characteristics of the combustion process. In this study, the RoHR was calculated by the AVL FIRE ESE Diesel platform, as the same as the method reported by Valentina Fraioli et al. in their contribution [71]. In the first combustion stage of the DF modes, although only a small amount of the diesel pilot fuel is injected into the combustion chamber, the RoHRs in all combustion cases are almost the same, including DF modes and diesel mode. This is because diesel premixed combustion is the main contributor to this combustion stage. In other words, the combustion characteristics in all combustion cases are almost the same in this stage. As soon as the diesel pilot fuel self-ignites to generate ignition sources, the gas-air premixed mixture immediately burns without any ignition delay of the premixed gas fuel. From the second stage of DF combustion, the premixed combustion of the primary fuel (gas) is the main contributor instead of the combustion of the diesel fuel. Figure 9 shows that in the second stage of combustion, the RoHRs of DF combustions are lower than those of diesel combustion and reduce in the order of $\mathrm{CH}_{4}{ }^{-}, \mathrm{C}_{2} \mathrm{H}_{6}{ }^{-}, \mathrm{C}_{3} \mathrm{H}_{8^{-}}$, and $\mathrm{C}_{4} \mathrm{H}_{10}$-diesel modes. This combustion stage occurs near the TDC, indicating that this stage plays a very important role in the in-cylinder pressure rise rate. Reductions in the RoHR in this combustion stage contribute to the reduction of the in-cylinder peak pressure. Because the RoHR decreases in the order of $\mathrm{CH}_{4}-\mathrm{C}_{2} \mathrm{H}_{6^{-}}, \mathrm{C}_{3} \mathrm{H}_{8^{-}}$, and $\mathrm{C}_{4} \mathrm{H}_{10}$-diesel modes, the in-cylinder peak pressure also reduces in the same order, as shown in Figure 10.

Another factor that affected the reduction in the in-cylinder peak pressure was the in-cylinder compression pressure of the premixed mixture of gas and charge air at the end of the compression process. In the DF modes, as shown in Table 1, since the specific heat capacities of gases are significantly higher than those of fresh air, the addition of 
gases in charged air increases the overall heat capacity of the gas-air premixed mixtures in the engine cylinder at the beginning of the compression process. This results in a reduction in the in-cylinder temperature at the end of the compression process in dual-fuel modes compared to that in the diesel mode, in which only fresh air is compressed in the compression process, as can be seen in Figure 12. Reductions in the in-cylinder temperature resulted in reductions in the in-cylinder pressure according to the real gas equation and, subsequently, reduced the in-cylinder peak pressure. All the stated factors caused the in-cylinder peak pressure in the DF modes to be lower than that in the diesel mode, as shown in Figure 10.

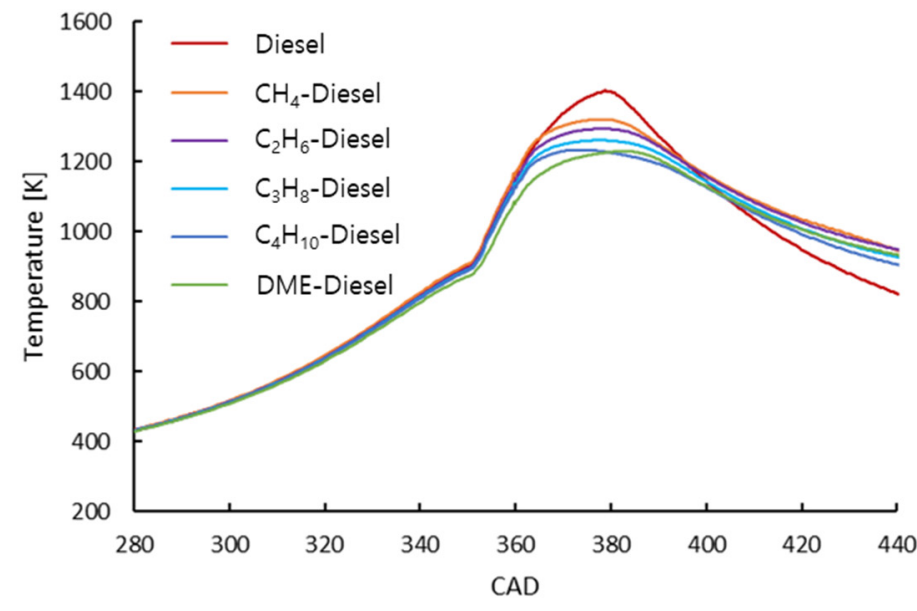

(a)

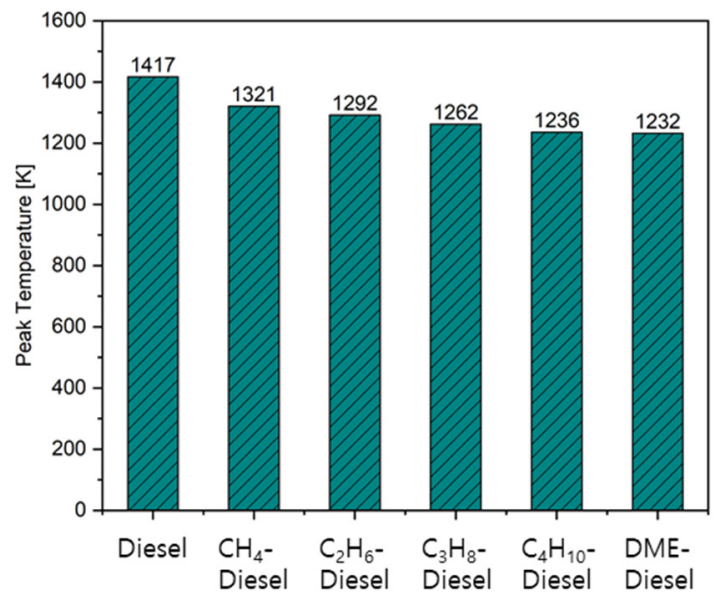

(b)

Figure 12. Mean in-cylinder temperature (a) and maximum in-cylinder temperature (b).

\subsection{In-Cylinder Temperature and NO Emission}

The in-cylinder temperature diagrams and peak temperatures for all cases of combustion are shown in Figure 12. The simulation results showed reductions of $6.75 \%, 8.82 \%$, $10.94 \%, 12.77 \%$, and $13.06 \%$ in the in-cylinder peak temperature for the $\mathrm{CH}_{4^{-}}, \mathrm{C}_{2} \mathrm{H}_{6^{-}}, \mathrm{C}_{3} \mathrm{H}_{8^{-}}$, $\mathrm{C}_{4} \mathrm{H}_{10^{-}}$, and DME-diesel DF fuel modes, respectively, compared to the diesel mode.

Similar to the reduction in the in-cylinder peak pressure presented in Section 3.2, the lower in-cylinder peak temperature in the DF modes is also due to the lean premixed combustion characteristics and slower burning rate of DF combustion. Two main factors affect the reduction in the in-cylinder temperature in DF modes: (1) the lower RoHRs at the second stage of the combustion and (2) lower compression temperature due to the effects of the higher overall heat capacity of the gas-air premixed mixture at the start of the compression process. The RoHRs in the second stage of the combustion were reduced together with reductions in the compression temperatures in the order of $\mathrm{CH}_{4}{ }^{-}$, $\mathrm{C}_{2} \mathrm{H}_{6^{-}}, \mathrm{C}_{3} \mathrm{H}_{8^{-}}, \mathrm{C}_{4} \mathrm{H}_{10^{-}}$, and DME-diesel DF modes, which reduced the in-cylinder peak temperature in the same order, as shown in Figure 12.

Figure 13 shows the $\mathrm{NO}$ emissions generated in all the combustions. Figure 13a shows the mean NO mass fraction in the engine cylinder according to the engine CADs, whereas Figure $13 \mathrm{~b}$ shows the specific NO emission $(\mathrm{g} / \mathrm{kWh})$. The results showed that the NO emissions generated in the DF modes were significantly reduced compared to those in the diesel mode, particularly when DME was used as the primary fuel in DF modes. The $\mathrm{NO}$ emissions generated in the diesel, $\mathrm{CH}_{4}-\mathrm{C}_{2} \mathrm{H}_{6^{-}}, \mathrm{C}_{3} \mathrm{H}_{8^{-}}, \mathrm{C}_{4} \mathrm{H}_{10^{-}}$, and DME-diesel DF modes were $7.63,1.98,2.232,2.033,1.813$, and $0.288 \mathrm{~g} / \mathrm{kWh}$, respectively. This means that NO emissions were reduced by up to more than $74.05 \%$ and $96.225 \%$ when the engine was operated in the $\mathrm{CH}_{4}$ - or DME-diesel DF modes, respectively, as shown in Figure 13b. 


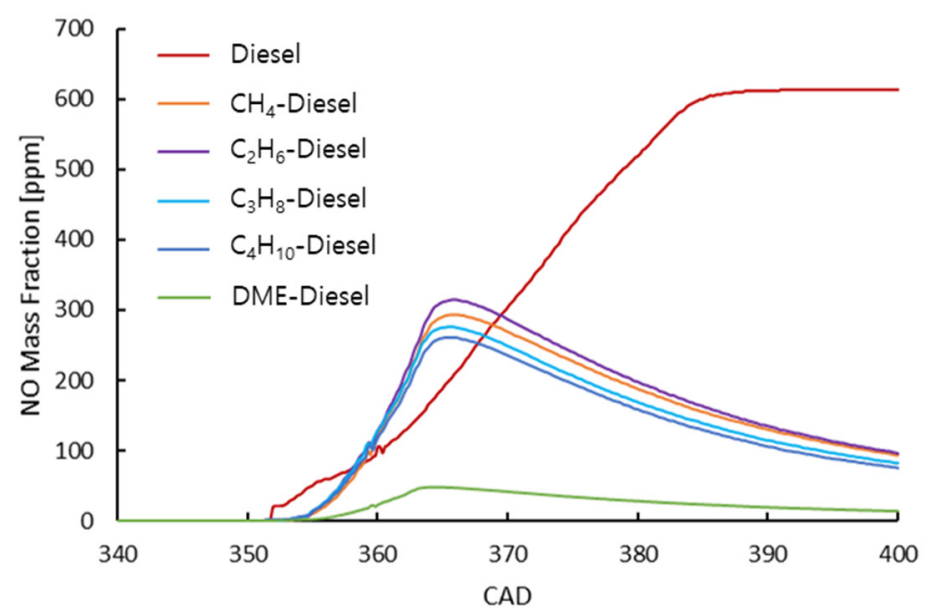

(a)

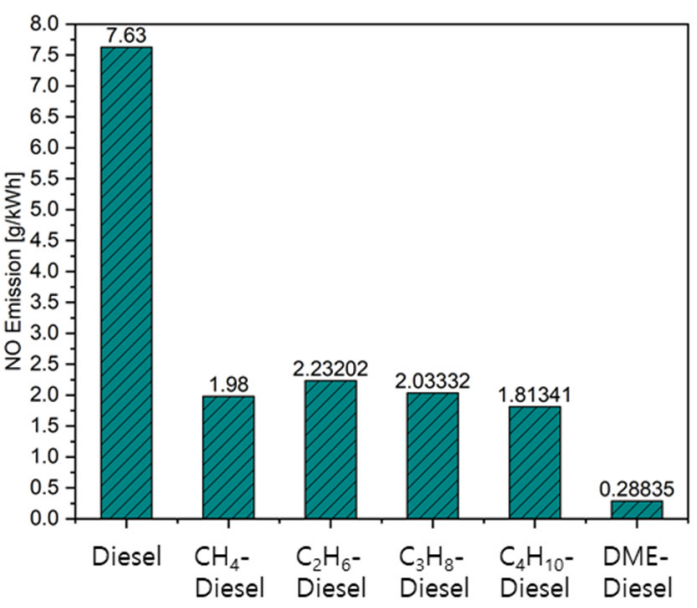

(b)

Figure 13. Mean NO mass fractions (a) and NO emission masses (b) in all combustion cases.

It is universally known that $\mathrm{NO}$ is the main component and usually occupies more than $90 \%$ of NOx emissions generated from internal combustion engines. Two typical chemical mechanisms are involved in NO formation: the thermal mechanism (Zeldovich mechanism) and the prompt mechanism (Fenimore mechanism) [36]. Because DF combustion is a leanburn combustion, the excess air ratio in the gas-diesel DF engine is larger than unity. Therefore, only the NO thermal mechanism must be considered. Therefore, the extended Zelodovich NO emission model was used to simulate the NO formation in this study. According to the thermal mechanism, $\mathrm{NO}$ formation is considerably influenced by the in-cylinder peak temperature and oxygen concentration within the engine cylinder. NO formation occurs in regions in the cylinder where the local temperature is above $1800 \mathrm{~K}$, and the formation rate increases significantly with an increase in the local in-cylinder temperature $[36,37,52]$.

To visualize the in-cylinder local temperature, the temperature contours at the $\mathrm{CA}$ positions covering the combustion duration, from 11 CAD BTDC (1 CAD after SOI) to 50 CAD ATDC, which have the highest in-cylinder temperature, are shown in Section 3.6. The temperature contours presented in Section 3.6 indicate that, at most of the CA positions, the local temperature inside the engine cylinder in the DF mode was lower than that in the diesel mode, resulting in a significant reduction in NO formation.

In the DF modes, gas fuel was injected into the intake port, which mixed with fresh air, generating a homogeneous premixed mixture prior to being supplied to the cylinder, resulting in a reduction in the local oxygen concentration within the engine cylinder. This reduces the $\mathrm{NO}$ emissions when burning DFs compared with burning diesel only.

Additionally, by analyzing the equivalence ratio-temperature diagram ( $\phi$-T diagram), we can qualitatively evaluate the thermal $\mathrm{NO}$ emission as well as soot formation in internal combustion engines [52]. Figure 14 shows the NOx-soot regions according to the equivalence ratio-temperature diagrams. In this figure, the regions bounded by the black curve represent a region where soot can be generated, while the region bounded by the red curve represents a region with the possibility of generating $\mathrm{NO}$ emission. As can be seen in Figure 14, NO emission was formed in regions with very high local temperatures but low equivalence ratios, whereas soot was formed in regions with high equivalence ratios and relatively high temperatures. The colored dots in the figure represent the crank angles (CAs) that occur in soot and/or NOx formations. For instance, the turquoise, brown, and green colors represent $C A s$ of $363^{\circ}, 375^{\circ}$, and $385^{\circ}$, respectively, while violet represents a $\mathrm{CA}$ of $343^{\circ}$. Figure 14 shows that, in the diesel mode, most NO formation occurs at CAs of $363^{\circ}, 375^{\circ}$, and $385^{\circ}$, where the in-cylinder local temperatures are highest owing to the combustion of fuel. Meanwhile, NO formation occurs almost only at 353 and 363 CADs (marked by purple and turquoise, respectively), where the local temperature in the cylinder 
is the highest in the DF mode. The figure also shows a much lower intensity of NO formation in the case of running the engine in the DF modes, particularly in the DME-diesel mode (there were the least colored dots in the NO-forming region).

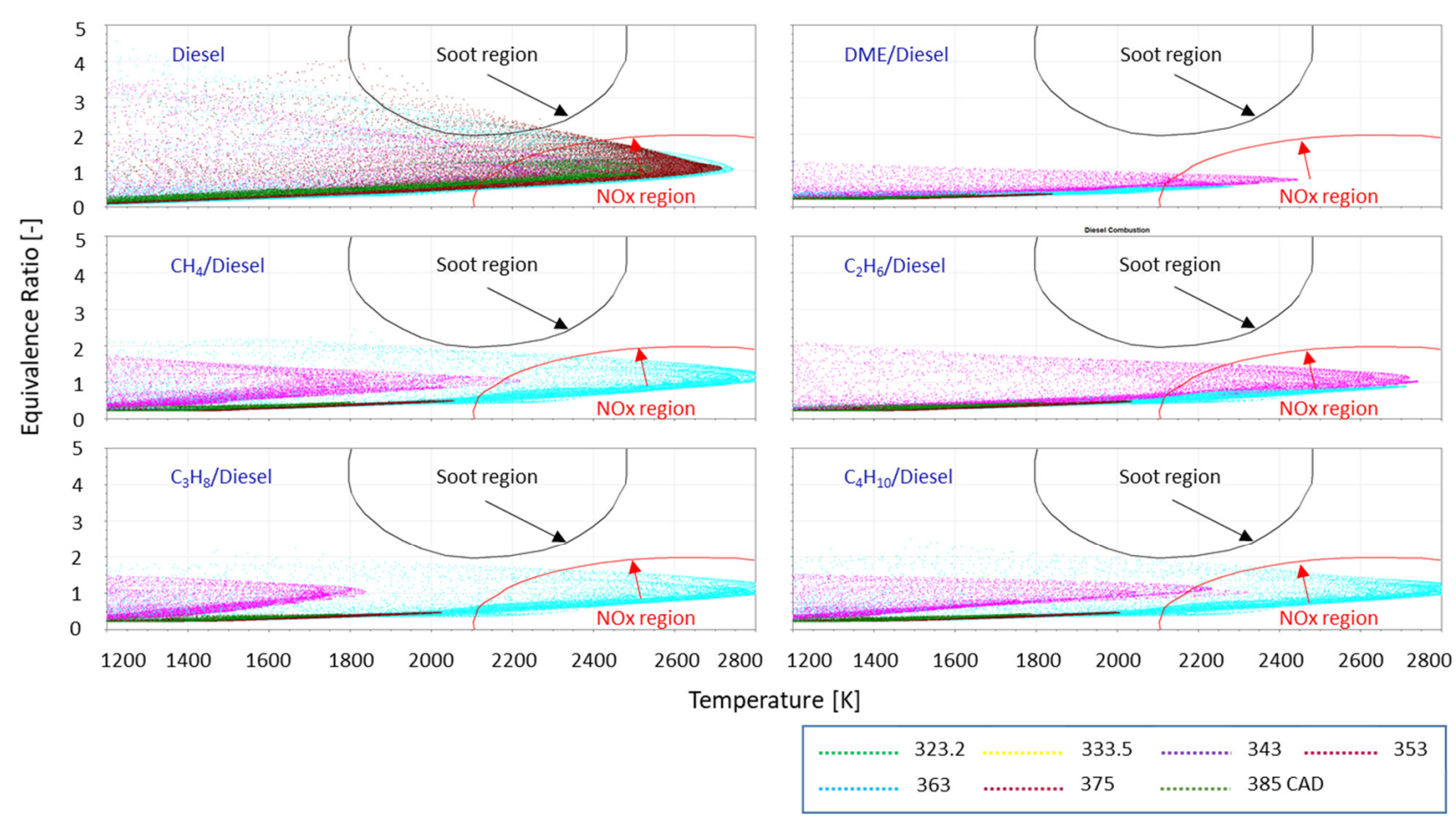

Figure 14. Equivalence ratio-temperature diagrams in all combustion cases.

\subsection{Soot Formation}

Soot is the main component of PM emissions [72-75]. Under high temperature and equivalence ratios (fuel-rich conditions), which are typically found in diesel diffusion combustions, hydrocarbon fuels have a strong tendency to form carbonaceous particles, i.e., soot. Under normal running conditions of engines, most soot formed in the early combustion stages is burnt due to oxidation with oxygen in oxygen-rich areas inside the combustion chamber in the later stage of combustions. In diesel engines, the completeness of the soot oxidation process and thus the final generated amount of soot actually determine their particle emission characteristics [60]. The local equivalence (fuel/air) ratio (C/O and $\mathrm{C} / \mathrm{H}$-ratio), pressure, temperature, and residence time play the most important role during soot formation of engines [60]. Soot particles are formed very early in the diffusion combustion process because of the dissociation of fuels under high temperature and high equivalence ratio conditions.

Chemically, under ideal conditions, the oxidation of hydrocarbon fuels and oxygen forms $\mathrm{CO}_{2}$ and $\mathrm{H}_{2} \mathrm{O}$. The amount of oxygen necessary for complete oxidations is called the stoichiometric oxygen requirement $\mathrm{O}_{2}$, stoichiometric, and can be calculated based on the following reaction equation [60]:

$$
\mathrm{C}_{n} \mathrm{H}_{m} \mathrm{O}_{k}+\left(n+\frac{m}{4}-\frac{k}{2}\right) \mathrm{O}_{2} \rightarrow n \mathrm{CO}_{2}+\frac{m}{2} \mathrm{H}_{2} \mathrm{O}
$$

where $k, n$, and $m$ respectively are the number of oxygen $(O)$, carbon $(C)$, and hydrogen $(H)$ atoms of the reacting fuel. 
The actual amount of oxygen available for combustion is expressed by the air access ratio $\lambda$ or by its inversion, the equivalence ratio $\phi$ :

$$
\phi=\frac{1}{\lambda}=\frac{O_{2, \text { stoichiometric }}}{O_{2}}
$$

The second important factor affecting the formation of soot is fuel structure. Studies in $[76,77]$ have emphasized that fuel structures have a strong effect on the polycyclic aromatic hydrocarbon (PAH) formations and soot in flames. This is because radicals influence the formation and growth of PAH and soot, such as methyl $\left(\mathrm{CH}_{3}\right)$, acetylene $\left(\mathrm{C}_{2} \mathrm{H}_{2}\right)$, and propargyl $\left(\mathrm{C}_{3} \mathrm{H}_{3}\right)$, which are strongly affected by fuel structure and its pyrolysis characteristics. Species formed by the pyrolysis of fuels first develop into incipient rings such as benzene $\left(\mathrm{C}_{6} \mathrm{H}_{6}\right)$ and naphthalene $\left(\mathrm{C}_{10} \mathrm{H}_{8}\right)$, then into PAHs, and finally, into soot [78-81]. Yoon et al. substantiated the importance of $\mathrm{CH}_{3}$ radicals in the formation of $\mathrm{C}_{3} \mathrm{H}_{3}$ and their effect on PAH formation and the subsequent growth of soot [79]. They showed that the more $\mathrm{CH}_{3}$ radicals there are, the more PAHs are formed and thus the greater the soot formation is.

Figure 15a shows the mean soot mass fraction in the engine cylinder according to the engine CADs, while Figure $15 \mathrm{~b}$ shows the specific soot emission ( $\mathrm{g} / \mathrm{kWh}$ ) in all combustion cases. The simulation results showed that the amount of soot generated was significantly reduced when the engine was operated in the DF modes. In particular, soot emission was reduced by up to $82.78 \%$ when the engine was operated in the $\mathrm{C}_{3} \mathrm{H}_{8}$-diesel DF mode, as shown in Figure 15b.

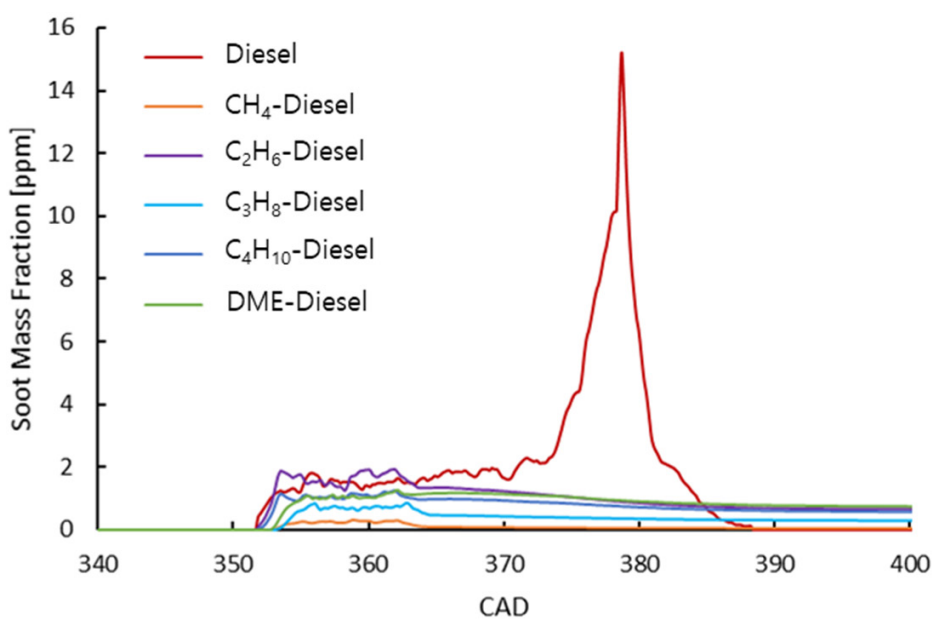

(a)

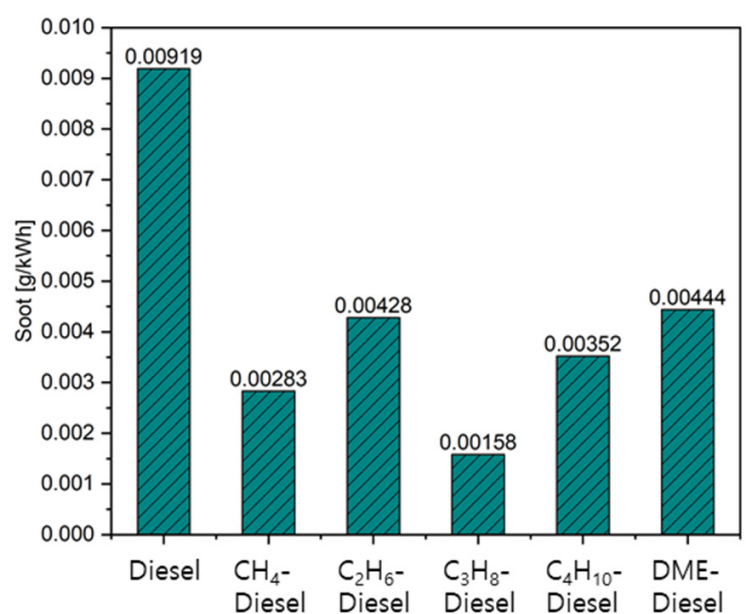

(b)

Figure 15. Mean soot mass fractions (a) and soot emission masses (b) in all combustion cases.

In DF combustion, gas is injected into the intake port; therefore, there is more time for the mixing process to generate a homogeneous pre-mixed mixture with fresh air for good combustion in the cylinder. A good mixing process results in a significant reduction in the local equivalence ratio within the combustion chamber. Even though there was a diesel diffusion combustion period that would promote soot formation when the diesel pilot fuel was injected directly into the engine cylinder in the DF mode, the mass of the injected diesel was very small (less than $5 \%$ of the total supplied energy); thus, the diffusion combustion period was very short. Javier Monsalve-Serrano et al. also reported in their publication that a lower pilot fuel quantity results in a lower soot formation [66]. Additionally, all gas fuels used in the DF modes contained fewer C atoms than diesel oil; thus, DF combustion generates less soot than diesel combustion. Additionally, the soot formed from the diffusion combustion of the diesel pilot fuel is then consumed by the combustion of a homogeneous gas-air premixed mixture, thus further reducing the soot emission in the DF modes [68]. 
We also compared the soot formations among the DF modes. Soot formation depends not only on the injected fuel amounts but also on fuel structures. As mentioned, the methyl $\left(\mathrm{CH}_{3}\right)$ radical generated from fuel pyrolysis processes plays an important role in the formation of $\mathrm{C}_{3} \mathrm{H}_{3}$ and thus indirectly affects $\mathrm{PAH}$ formation and the subsequent growth of soot. In other words, soot formation in the DF modes using various gas fuels was mainly influenced by the $\mathrm{CH}_{3}$ radicals generated from the fuel pyrolysis processes.

Figure $15 \mathrm{~b}$ shows that soot formed from combustion in the DME- and $\mathrm{C}_{2} \mathrm{H}_{6}$-diesel modes is the highest, whereas that formed from the $\mathrm{C}_{3} \mathrm{H}_{8}$-diesel mode is the least. This is because dimethyl ether $\left(\mathrm{CH}_{3} \mathrm{OCH}_{3}\right)$ contains two methyl radicals, whereas the pyrolysis of $\mathrm{C}_{2} \mathrm{H}_{6}$ also generates two methyl radicals $\left(\mathrm{C}_{2} \mathrm{H}_{6} \rightarrow 2 \mathrm{CH}_{3}\right)$ [82]. These methyl radicals promote $\mathrm{PAH}$ formation; therefore, their combustion forms more soot compared to the other cases, as shown in Figure 15b. Regarding the higher amount of soot in the DME-diesel mode compared to that in the $\mathrm{C}_{2} \mathrm{H}_{6}$-diesel mode, even though the pyrolysis processes of both DME and $\mathrm{C}_{2} \mathrm{H}_{6}$ generate two methyl radicals, the amount of DME used in the DME-diesel mode is larger than that amount of $\mathrm{C}_{2} \mathrm{H}_{6}$ used in the $\mathrm{C}_{2} \mathrm{H}_{6}$-diesel mode owing to its low LCV (shown in Table 1), resulting in higher soot formation. In the three remaining DF modes, the pyrolysis processes of $\mathrm{CH}_{4}, \mathrm{C}_{3} \mathrm{H}_{8}$, and $\mathrm{C}_{4} \mathrm{H}_{10}$ generated only one methyl radical $\left(\mathrm{CH}_{4} \rightarrow \mathrm{CH}_{3}+\mathrm{H}, \mathrm{C}_{3} \mathrm{H}_{8} \rightarrow \mathrm{CH}_{3}+\mathrm{C}_{2} \mathrm{H}_{5}\right.$, and $\left.\mathrm{C}_{4} \mathrm{H}_{10} \rightarrow \mathrm{CH}_{3}+\mathrm{C}_{3} \mathrm{H}_{7}\right)$ [83-85]. Among these three cases, the higher soot formation in the $\mathrm{C}_{4} \mathrm{H}_{10}$-diesel mode is because the amount of $\mathrm{C}_{4} \mathrm{H}_{10}$ used in the $\mathrm{C}_{4} \mathrm{H}_{10}$-diesel mode was larger than the amount of $\mathrm{C}_{3} \mathrm{H}_{8}$ used in the $\mathrm{C}_{3} \mathrm{H}_{8}$-diesel mode and $\mathrm{CH}_{4}$ used in the $\mathrm{CH}_{4}$-diesel mode because of its lower LCV (shown in Table 1), resulting in a higher soot formation. The amount of soot generated in the $\mathrm{C}_{3} \mathrm{H}_{8}$-diesel mode was lower than that in the $\mathrm{CH}_{4}$-diesel mode, which could be explained as follows: during the pyrolysis of $\mathrm{CH}_{4}\left(\mathrm{CH}_{4} \rightarrow \mathrm{CH}_{3}+\mathrm{H}\right)$ [83], $1 \mathrm{~mol}$ of $\mathrm{CH}_{4}$ with a mass of $16 \mathrm{~g}$ produces 1 mol of $\mathrm{CH}_{3}$ with a mass of $15 \mathrm{~g}$ and $1 \mathrm{~mol}$ of $\mathrm{H}$ atom with a mass of $1 \mathrm{~g}$. The mass fraction of $\mathrm{CH}_{3}$ in the fuel during pyrolysis was 15/16. Meanwhile, during the pyrolysis of $\mathrm{C}_{3} \mathrm{H}_{8}\left(\mathrm{C}_{3} \mathrm{H}_{8} \rightarrow \mathrm{CH}_{3}+\mathrm{C}_{2} \mathrm{H}_{5}\right)$ [84], 1 mol of $\mathrm{C}_{3} \mathrm{H}_{8}$ with a mass of $44 \mathrm{~g}$ produced $1 \mathrm{~mol} \mathrm{CH}_{3}$ with a mass of $15 \mathrm{~g}$ and $1 \mathrm{~mol}$ of $\mathrm{C}_{2} \mathrm{H}_{5}$ with a mass of $29 \mathrm{~g}$. The mass fraction of $\mathrm{CH}_{3}$ in the fuel during pyrolysis was 15/44, which is less than that of $\mathrm{CH}_{4}$ in the fuel. The lower mass fraction of $\mathrm{CH}_{3}$ in the fuel during the pyrolysis of $\mathrm{C}_{3} \mathrm{H}_{8}$ fuel compared to that of $\mathrm{CH}_{4}$ in the fuel resulted in a reduction in soot formation in the $\mathrm{C}_{3} \mathrm{H}_{8}$-diesel mode, as shown in Figure $15 \mathrm{~b}$.

Qualitatively, as mentioned above, using the NOx-soot regions according to the equivalence ratio-temperature diagram shown in Figure 14, it can be observed the engine's CAs at which the high local equivalence ratios occurred are accompanied with hightemperature, which result in high soot formation. Figure 14 shows that in the DF modes, the local equivalence ratios within the engine cylinder were remarkably reduced because only a small amount of diesel pilot fuel was injected directly into the engine cylinder. There were virtually no high equivalence ratios in the soot area, indicating that soot formation was significantly reduced, as shown quantitatively in Figure $15 \mathrm{~b}$.

\subsection{Carbon Dioxide $\left(\mathrm{CO}_{2}\right)$ Emissions}

The $\mathrm{CO}_{2}$ emissions generated inside the engine cylinder for all combustion cases are shown in Figure 16. The simulation results indicated that the $\mathrm{CO}_{2}$ formation in all cases of DF combustion, particularly in the $\mathrm{CH}_{4}$-diesel mode, was lower than that in the diesel combustion case. The $\mathrm{CO}_{2}$ emissions in the diesel, DME-, $\mathrm{C}_{4} \mathrm{H}_{10^{-}}, \mathrm{C}_{3} \mathrm{H}_{8^{-}}, \mathrm{C}_{2} \mathrm{H}_{6^{-}}$, and $\mathrm{CH}_{4}$-diesel modes were $0.05918,0.05682,0.05596,0.05268$, and $0.04656 \mathrm{~g} / \mathrm{kWh}$, respectively. This implies that the $\mathrm{CO}_{2}$ emission was reduced in the DF mode compared to that in the diesel mode. The $\mathrm{CO}_{2}$ emission reduction in the $\mathrm{CH}_{4}$-diesel mode was the largest at $21.33 \%$. 


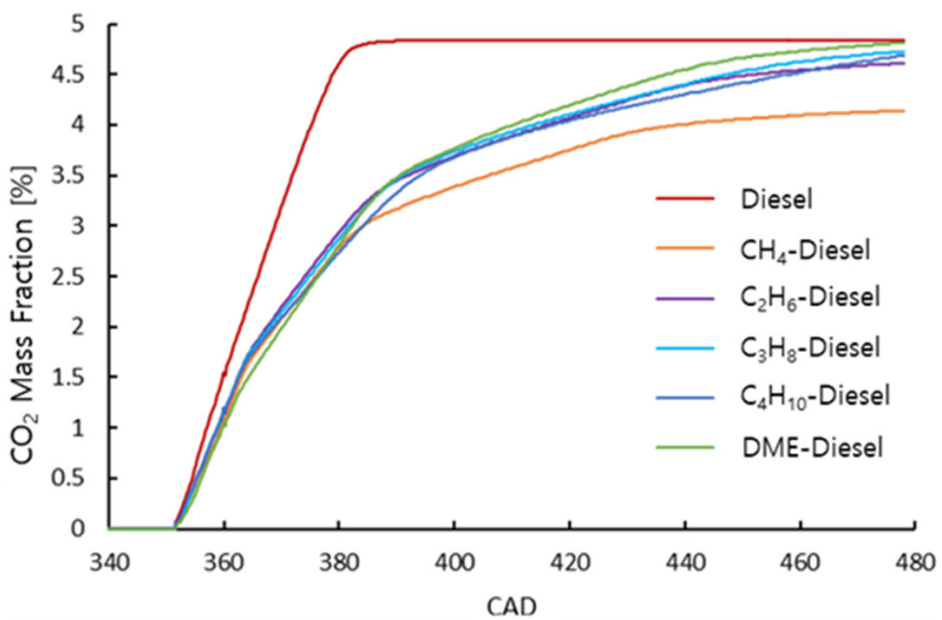

(a)

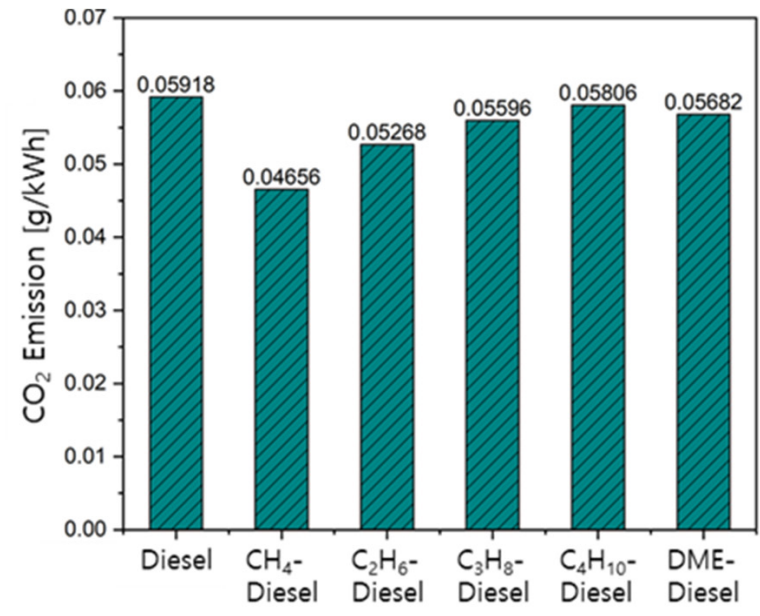

(b)

Figure 16. Mean $\mathrm{CO}_{2}$ mass fractions (a) and $\mathrm{CO}_{2}$ emission masses (b) in all combustion cases.

Regarding the reasons for reductions in the $\mathrm{CO}_{2}$ emissions in the DF modes, as known, $\mathrm{CO}_{2}$ is a carbon-based emission. Therefore, the formation of $\mathrm{CO}_{2}$ directly depends on the number of carbon $(\mathrm{C})$ atoms contained in fuels and on the quality of combustion. $\mathrm{CO}_{2}$ is a product of the complete combustion of hydrocarbon fuels. First, hydrocarbon fuels are oxidized to $\mathrm{CO}$ due to the oxidation process with oxygen, and then, $\mathrm{CO}$ is oxidized to form $\mathrm{CO}_{2}$ sequentially if the temperature inside the cylinder is high enough and there is still enough $\mathrm{O}_{2}$ for oxidation. Therefore, the $\mathrm{CO}_{2}$ formation strongly depends on the temperature and the oxygen concentration inside the engine cylinder.

As mentioned above, all gas fuels used in the DF modes contain fewer $\mathrm{C}$ atoms than diesel oil, and in DF modes, gas is injected into the intake port in the intake stroke; thus, enough time is available to generate a good-quality homogeneous premixed mixture for good combustion in the cylinder. Therefore, the combustion of gas will produce less $\mathrm{CO}_{2}$ than diesel combustion. Additionally, the total amount of fuel used in the DF modes is less than that in the diesel mode owing to their higher LCVs. Therefore, the absolute $\mathrm{CO}_{2}$ emissions generated in the DF modes which use gas as the primary fuel were lower than those in the diesel mode.

Comparing the $\mathrm{CO}_{2}$ emissions among the DF modes, as shown in Figure $16 \mathrm{~b}$, the $\mathrm{CO}_{2}$ emissions decreased in the order of $\mathrm{C}_{4} \mathrm{H}_{10^{-}}$, DME-, $\mathrm{C}_{3} \mathrm{H}_{8^{-}}, \mathrm{C}_{2} \mathrm{H}_{6}$-, and $\mathrm{CH}_{4}$-diesel modes. As mentioned, because $\mathrm{CO}_{2}$ is a carbon-based emission, its formation directly depends on the number of $\mathrm{C}$ atoms contained in fuels, and a greater number of $\mathrm{C}$ atoms leads to higher $\mathrm{CO}_{2}$ emission levels. This means that $\mathrm{CO}_{2}$ emissions increase with an increase in the number of $\mathrm{C}$ atoms in the fuel used. In the case of DME fuel, the oxygen content in DME fuel $\left(\mathrm{CH}_{3} \mathrm{OCH}_{3}\right)$ further promotes the oxidation of $\mathrm{CO}$ to form $\mathrm{CO}_{2}$, resulting in an increase in $\mathrm{CO}_{2}$ to the same level as that in $\mathrm{C}_{3} \mathrm{H}_{8}$ fuel, even though DME contains fewer $\mathrm{C}$ atoms than $\mathrm{C}_{3} \mathrm{H}_{8}$ fuel.

\subsection{Ignition Delay}

Figure 17 shows the temperature distributions at the SOI and start of combustion (SOC) CADs in all combustion cases on the central plane of the engine cylinder for ignition delay analysis. Owing to the symmetrical characteristics of the engine combustion chamber and the pilot nozzle, the haft of the 2D model contours on the central plane is sufficient to analyze the temperature fields inside the engine cylinder. 


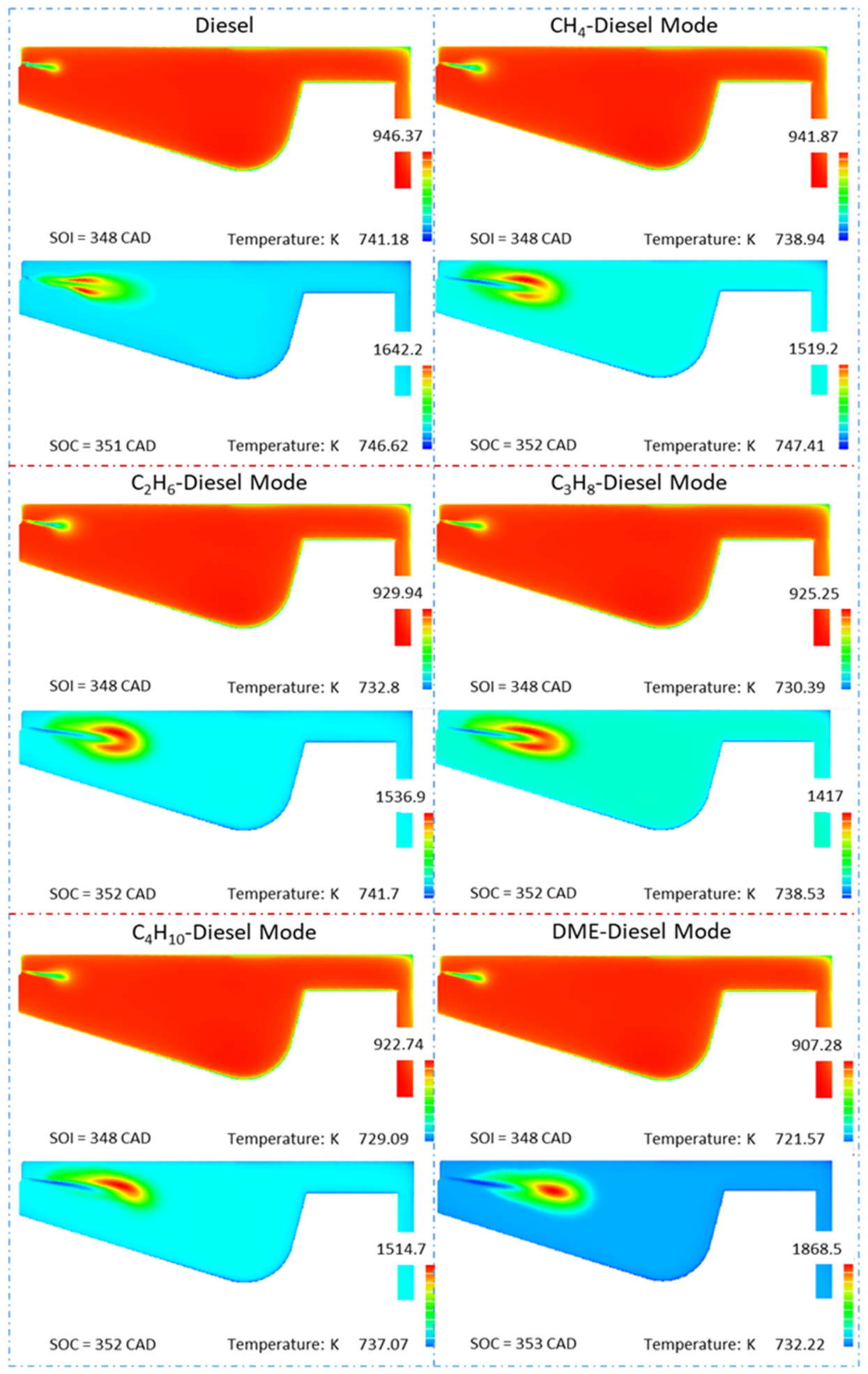

Figure 17. Spatial in-cylinder temperature contours at SOI and SOC crank angle degrees.

The SOI of diesel in the diesel mode and pilot fuel (diesel also) in the DF mode are $348 \mathrm{CAD}$. The diesel fuel could not ignite as soon as it was injected into the engine combustion chamber; thus, the temperature of the fuel beam (shown in green and yellow) was much lower than the in-cylinder temperature of the engine (shown in dark red). After a few milliseconds, after having received enough heat to evaporate and raise the temperature up to the flash point of the fuel, the diesel oil begins to self-ignite, causing the temperature at the core of the fuel beam to dramatically increase (shown in dark red), marking the 
start of the combustion of the fuel in the engine cylinder. As soon as the fuel burns, the temperature in other areas in the engine combustion chamber does not receive heat in time; thus, the temperature remains much lower than that at the core of the fuel beam (shown in green). As the ignition delay time is the interval time from SOI timing to the SOC timing, as shown in Figure 17, the ignition delay time of the fuel in the combustion cases can be qualitatively observed.

Figure 17 shows that diesel oil in the diesel mode ignited sooner than that in the DF modes. In particular, the SOC angle in the diesel mode was $351 \mathrm{CAD}$, whereas it was $352 \mathrm{CAD}$ in the $\mathrm{CH}_{4^{-}}, \mathrm{C}_{2} \mathrm{H}_{6^{-}}, \mathrm{C}_{3} \mathrm{H}_{8^{-}}$, and $\mathrm{C}_{4} \mathrm{H}_{10}$-diesel modes, and $353 \mathrm{CAD}$ in the DME-diesel mode.

The ignition delay times for all combustion cases are shown in Figure 18. Regarding the longer ignition delay time in the DF modes, the specific heat capacity of the gas is significantly higher than that of fresh air. Therefore, the addition of a gas in charged air increases the overall heat capacity of the gas-air premixed mixture in the engine cylinder at the start of the compression process. This reduces the temperature of the premixed mixture inside the cylinder at the end of the compression process (compression temperature $\mathrm{Tc}$ ), as can be seen in Figures 12 and 17. It is more difficult for diesel oil to self-ignite at a lower temperature and not in a pure fresh air environment compared with when it is injected into an environment of pure fresh air having a higher temperature, as in the diesel mode.

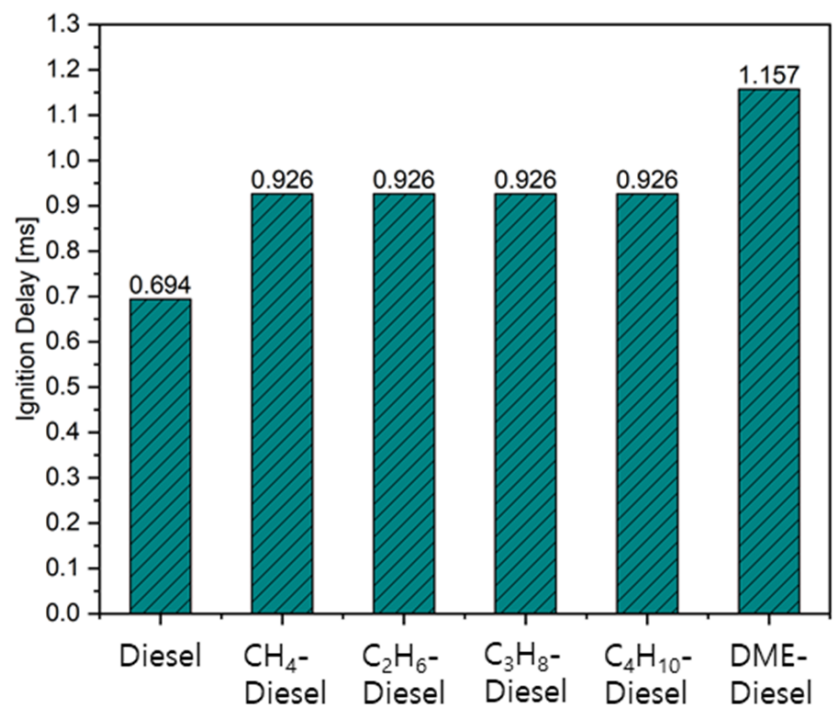

Figure 18. Ignition delay time in all combustion cases.

Comparing the DF modes, the ignition delay times for the $\mathrm{CH}_{4}-, \mathrm{C}_{2} \mathrm{H}_{6}-, \mathrm{C}_{3} \mathrm{H}_{8}-$, and $\mathrm{C}_{4} \mathrm{H}_{10}$-diesel modes were the same because the temperatures inside the cylinder at the end of the compression process were almost the same in these modes. Meanwhile, the ignition delay time in the DME-diesel mode was the longest. This is because the lowest in-cylinder temperature at the end of compression due to the highest specific heat of the DME leads to the longest ignition delay in the DME-diesel mode.

\subsection{Effects of the Injection Timing on Combustion and NO Emission}

To analyze the effect of the SOI angle on the emission formations and combustion process of the engine, numerous simulations were performed. In the diesel mode, diesel fuel was injected into the cylinder at four different SOI angles: 345 CAD (15 CAD BTDC), 348 CAD (12 CAD BTDC), 351 CAD (9 CAD BTDC), and 354 CAD (6 CAD BTDC). In addition, in DF modes, the diesel pilot fuel was injected into the cylinder at four different SOI angles, 345, 348, 351, and 354 CAD, whereas the gas fuel was still injected during the intake stroke. The simulation results are presented in this subsection as follows. 


\subsubsection{In-Cylinder Pressure and Temperature}

The mean in-cylinder pressure diagrams and peak pressures according to the change in diesel (pilot) SOI angles in all combustion modes are shown in Figures 19 and 20, respectively. The results showed reduction tendencies in peak pressures as the SOI angles decreased in most cases of combustion because of the shorter ignition time of the diesel oil when the SOI angle decreased. Only a slight difference in the $\mathrm{C}_{2} \mathrm{H}_{6}$-diesel mode was observed, in which the peak pressure also decreased as the SOI angles decreased from 12 CAD BTDC to 6 CAD BTDC; however, it also slightly decreased when the SOI angle increased from 12 CAD BTDC to 15 CAD BTDC. This can be explained by the fact that in the $\mathrm{C}_{2} \mathrm{H}_{6}$-diesel mode, the RoHR in the case of an SOI angle of $348 \mathrm{CAD}$ is the highest, as shown in Figure 21. A higher RoHR at a CAD closer to the TDC results in a higher increase in the maximum pressure in the cylinder. In contrast, in the other modes, the maximum RoHRs were reduced when the SOI angle was reduced. In addition, the reduction in the peak pressure when the SOI angle was reduced was due to the ignition delay times of diesel oil becoming shorter when the SOI angle decreased, as is well known. During the ignition delay times, the fuel was continuously injected into the cylinder; therefore, a reduction in the ignition delay times led to a decrease in the fuel mass that had accumulated before the start of combustion, causing a decrease in the in-cylinder peak pressure of the combustions.
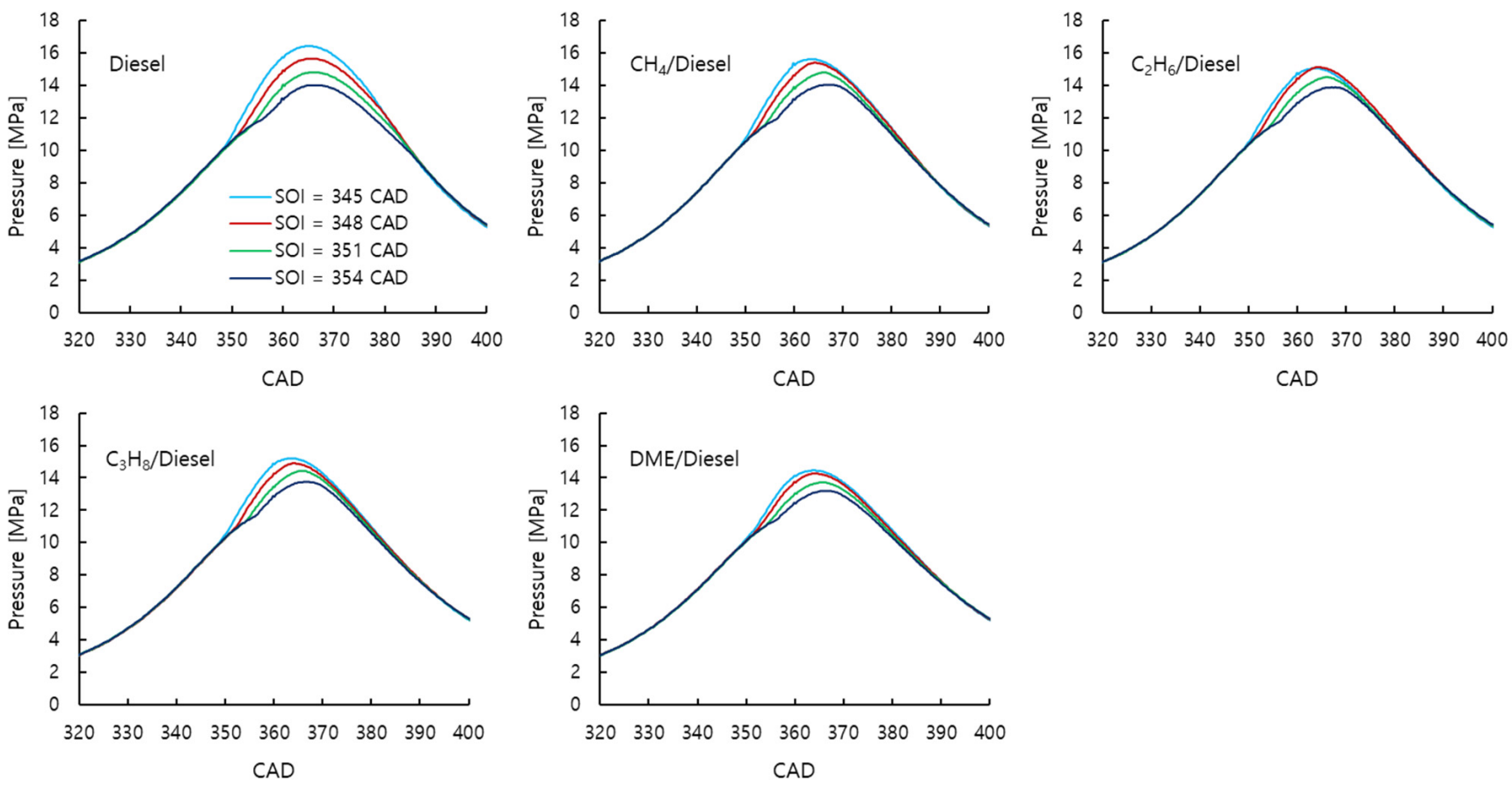

Figure 19. In-cylinder pressure diagrams according to pilot SOI angles in all combustion modes.

Additionally, Figure 21 also shows that when the SOI angle was reduced, the RoHR tended to increase in the late stage of combustion. However, these increases in the RoHR in this combustion stage only increased the in-cylinder temperature (as can be seen in Figure 22), while they had no effect on the in-cylinder pressure increase due to the piston moving away from the TDC.

Figures 22 and 23 show the mean in-cylinder temperature diagrams and peak temperature according to the change in the diesel (pilot) SOI angles in all combustion modes, respectively. The results also showed reduction tendencies in peak temperature as the SOI angles decreased in most cases of the combustion because of the shorter ignition time of the diesel oil when the SOI angle decreased, except for a slight difference in the $\mathrm{C}_{2} \mathrm{H}_{6}$-diesel mode, as explained above. Similar to the peak pressure, in this mode, the peak temperature decreased as the advanced injection angles decreased from 12 CAD BTDC 
to 6 CAD BTDC; however, it also slightly decreased when the advanced injection angles increased from 12 CAD BTDC to 15 CAD BTDC. From these results, it can be concluded that the advanced injection angle of 12 CAD BTDC gives the highest peak pressure and temperature in the $\mathrm{C}_{2} \mathrm{H}_{6}$-diesel mode, whereas in the other modes, the peak pressure and temperature decrease with decreasing SOI angles.

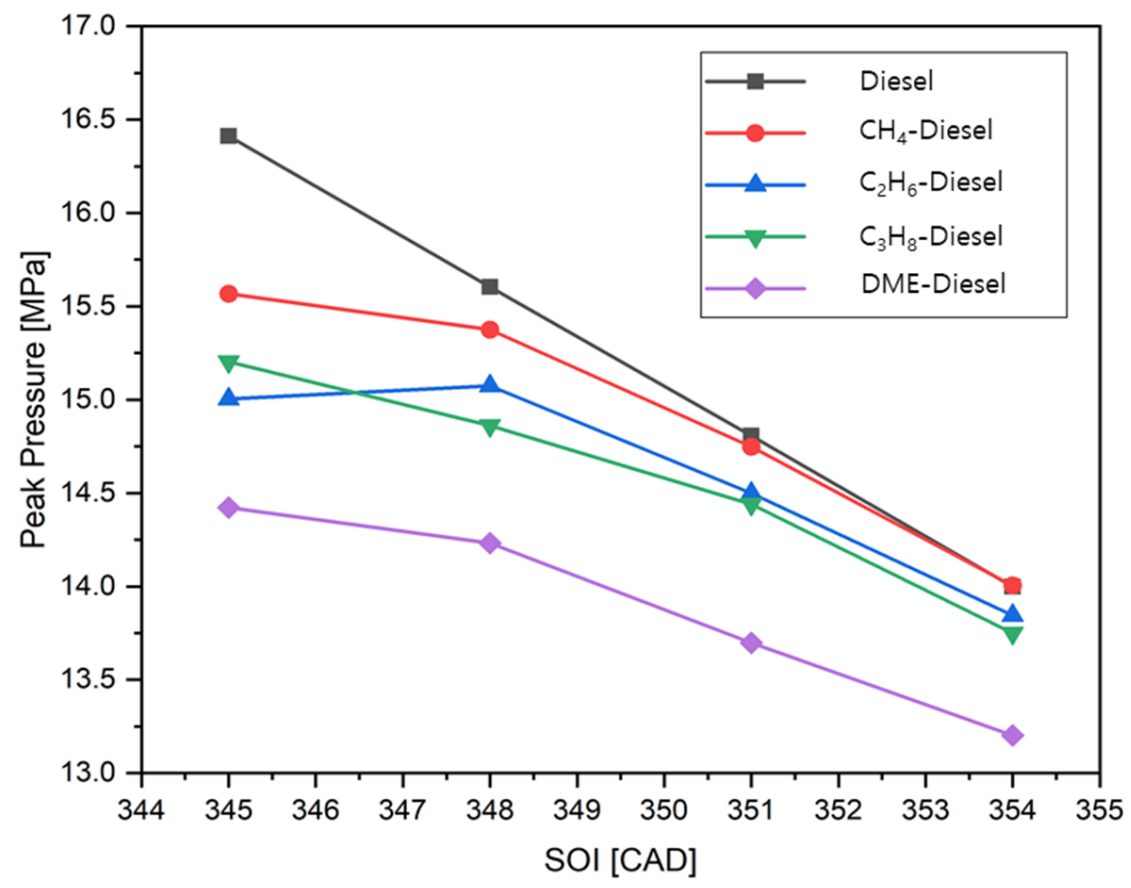

Figure 20. Maximum pressure according to pilot SOI angles in all combustion modes.
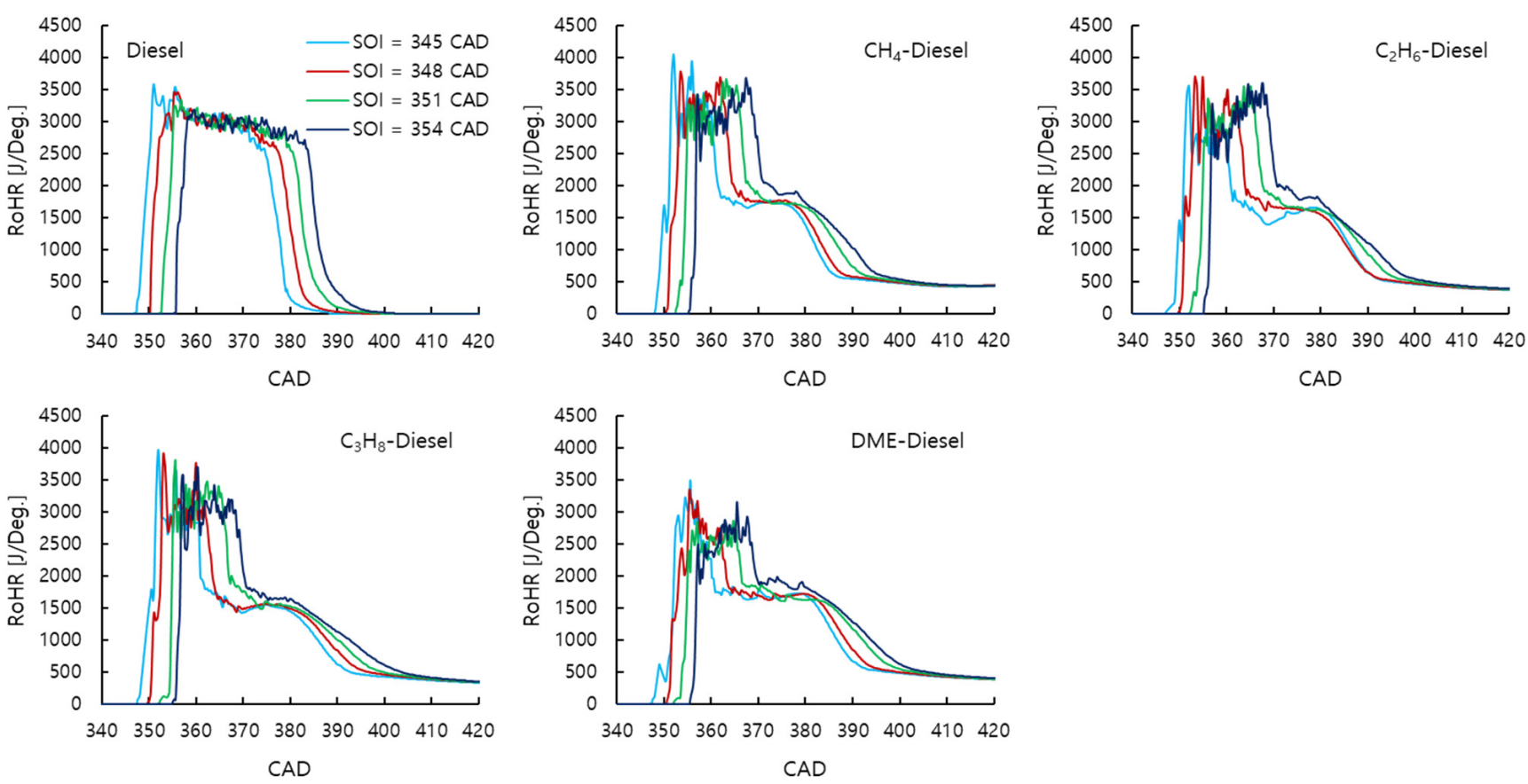

Figure 21. Rate of heat release diagrams according to pilot SOI angles in all combustion modes. 

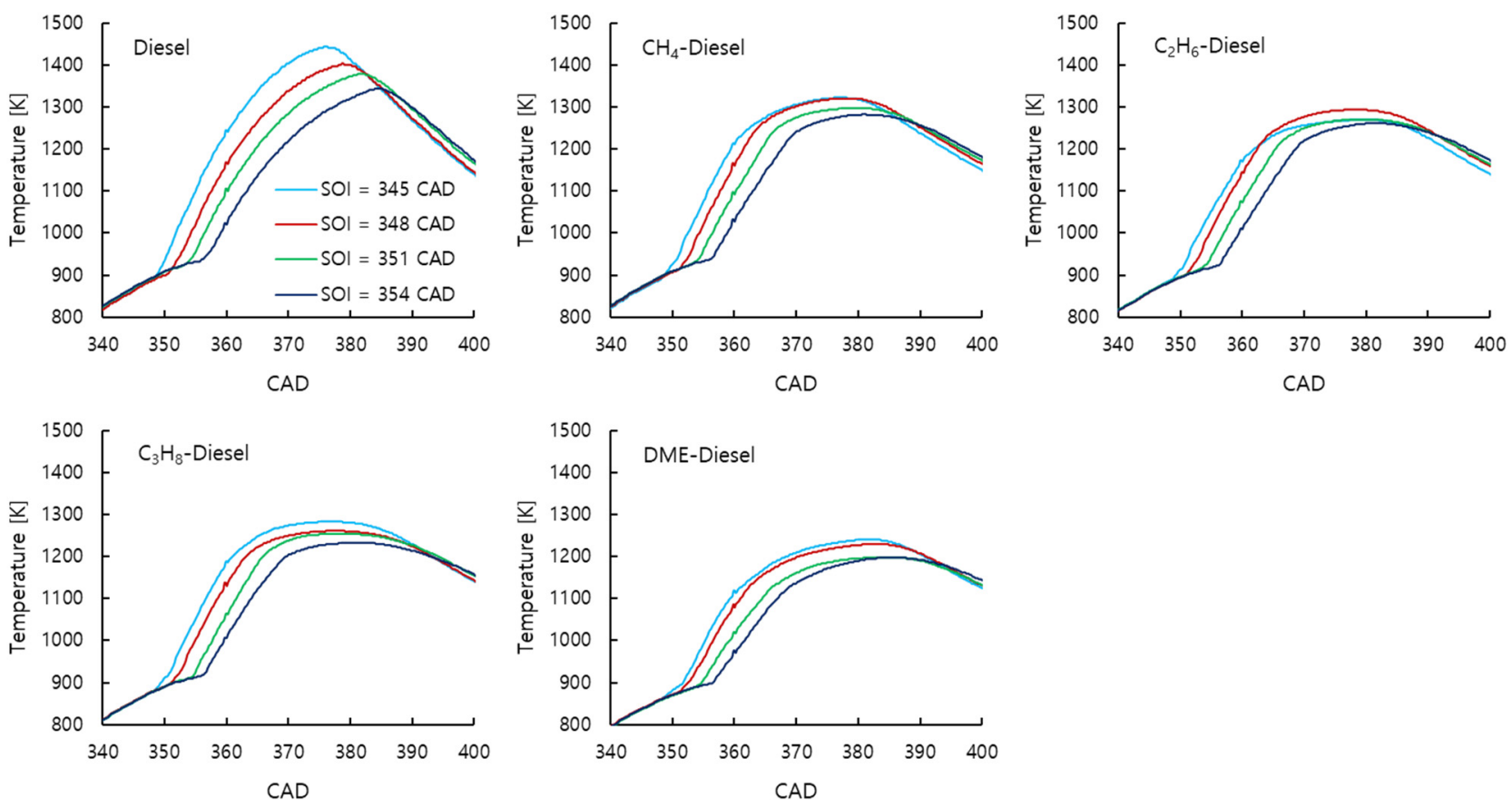

Figure 22. In-cylinder temperature diagrams according to pilot SOI angles in all combustion modes.

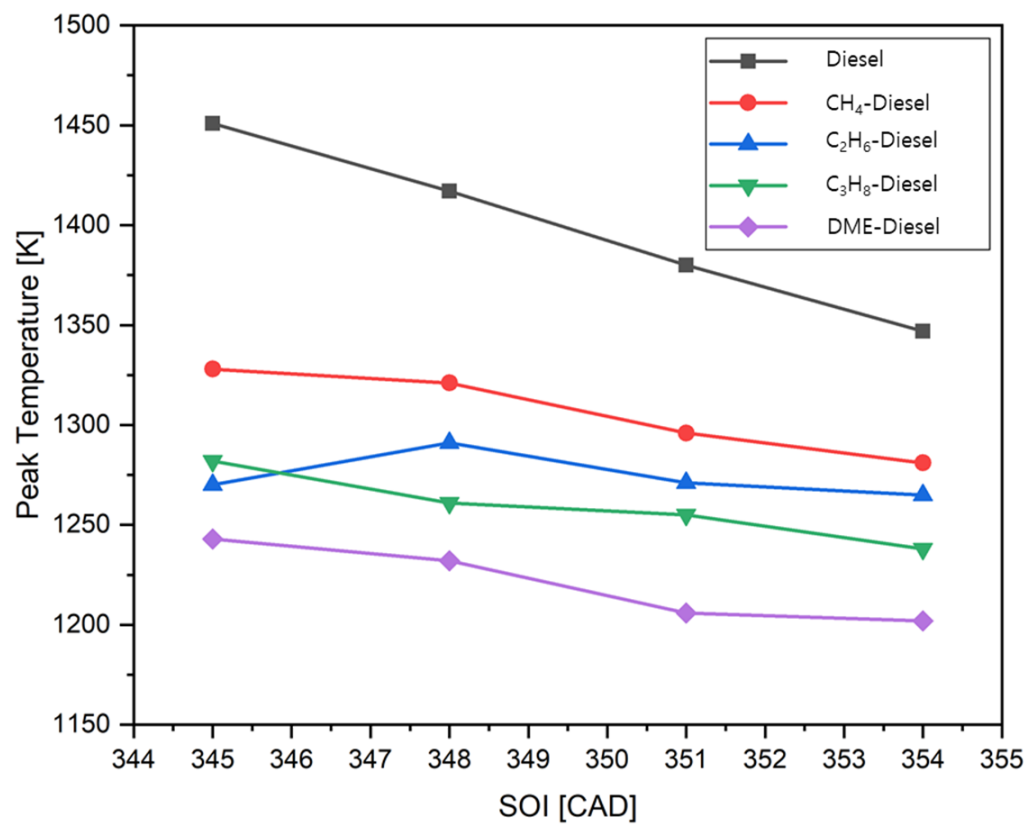

Figure 23. Peak temperature according to pilot SOI angles in all combustion modes.

\subsubsection{NO Emission}

The NO emission formations during combustion and the synthesis of NO mass fractions according to the pilot SOI angles in all combustion modes are shown in Figures 24 and 25, respectively. The results showed that in the diesel mode, the NO emissions decreased when the SOI angle changed from 345 to 354 CAD. Meanwhile, in the DF mode, the NO emission reached the highest value at the SOI angle of $348 \mathrm{CAD}$ and then tended to decrease or remained mostly unchanged when the SOI angle decreased from 348 CAD to $354 \mathrm{CAD}$, as shown in Figure 24. This provides a useful method to further reduce NO emissions, which involves reducing the SOI angle from $348 \mathrm{CAD}$ in all operating modes. 

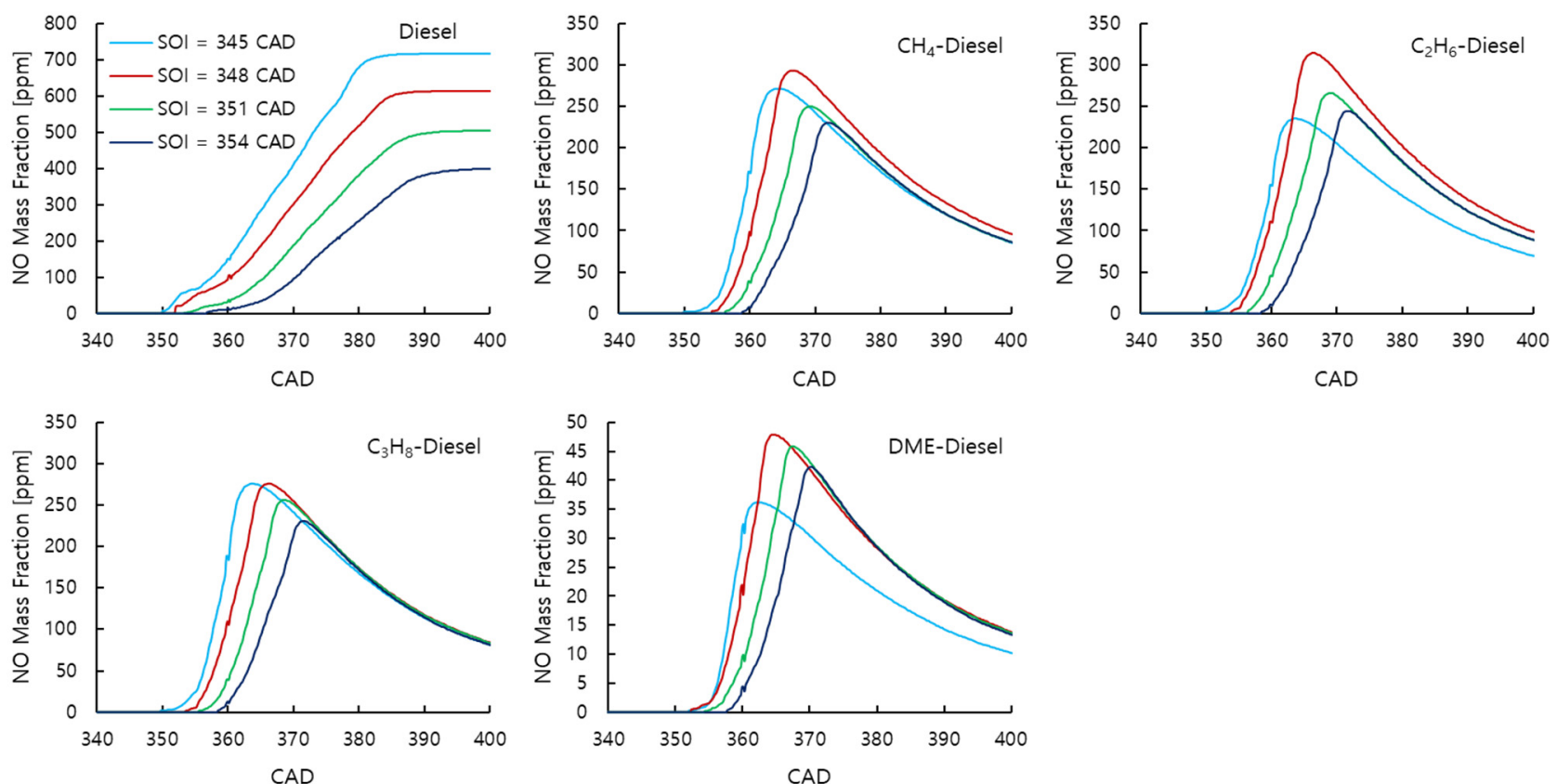

Figure 24. NO emission formations during combustions according to pilot SOI angles in all combustion modes.

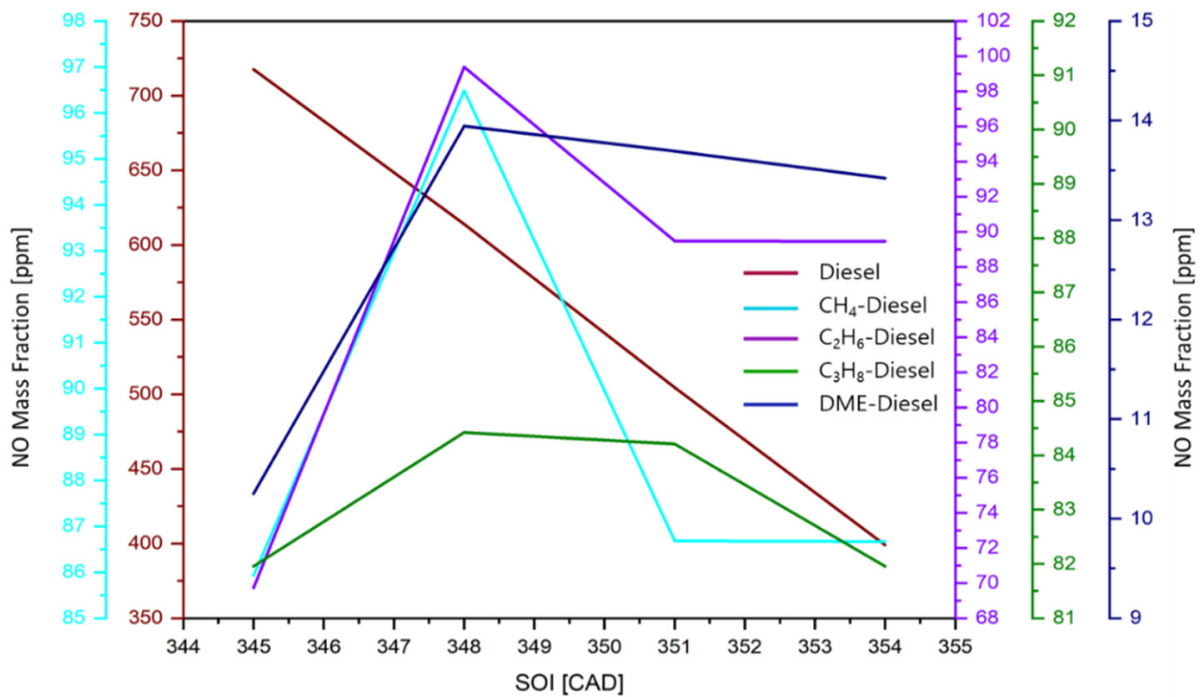

Figure 25. Synthetic of NO mass fractions according to pilot SOI angles in all combustion modes.

As shown in Figure 23, the in-cylinder peak temperature tended to decrease when the SOI angle decreased. This results in a decrease in NO formation, as is widely known. Similar to the diesel mode, in DF modes, NO emissions tended to decrease when the SOI angle decreased from 348 CAD to 354 CAD. However, in contrast to the diesel mode, in the $\mathrm{DF}$ mode, at the SOI angle of $345 \mathrm{CAD}$, the $\mathrm{NO}$ emissions generated were lower than those at other SOI angles. It is known that NO formation strongly depends on the local temperature in the engine cylinder. This tendency implies that a very high local temperature $(\geq 1800 \mathrm{~K})$ within the engine combustion chamber in cases of the $345 \mathrm{CAD}$ in DF modes was much lower than that in the case of other SOI angles. Therefore, in most DF modes, operating the engine at an SOI angle of 345 CAD can help further reduce NO emissions.

Importantly, the engine power changes as the SOI angle changes. Therefore, while selecting an SOI angle for each operating mode, the effects of the SOI angle on the engine power must be considered. Figure 26 shows the engine powers according to the changes in 
the SOI angles. The results showed that the engine power first remained almost unchanged when the SOI angle decreased from $345 \mathrm{CAD}$ to $348 \mathrm{CAD}$ and then tended to decrease if the SOI angle was further reduced in the diesel mode. Meanwhile, in the DF modes, the engine power tended to increase when the SOI angle decreased from $345 \mathrm{CAD}$, reached the maximum power, and then, decreased if the SOI angle continued to decrease. The engine reached its optimal power at an SOI angle of $348 \mathrm{CAD}$ in the diesel, $\mathrm{CH}_{4}^{-}$, and DME-diesel modes, whereas the optimal power was observed at SOI angles of $351 \mathrm{CAD}$ in the $\mathrm{C}_{2} \mathrm{H}_{6}$ - and $\mathrm{C}_{3} \mathrm{H}_{8}$-diesel modes. This implies that the combustion inside the engine cylinder reached the best condition and efficiency at $348 \mathrm{CAD}$ when the engine worked in the diesel mode or the $\mathrm{CH}_{4}$ - and DME-diesel modes. Similarly, the engine achieved the best combustion condition to obtain the best combustion efficiency and generated the highest power at an $\mathrm{SOI}$ angle of $351 \mathrm{CAD}$ in the $\mathrm{C}_{2} \mathrm{H}_{6}$ - and $\mathrm{C}_{3} \mathrm{H}_{8}$-diesel modes. Considering both economic and emission aspects, we conclude that applying emission reduction methods may result in some penalties in the economic efficiency of the engine; therefore, we must consider which aspects of the performance we want to optimize prior to applying any emission reduction method. In this study, after considering both engine power and NO emission performance aspects, we recommend the operators should operate the engine with an SOI angle of $351 \mathrm{CAD}$ to get better NO emission performance while keeping the engine output mostly unchanged.

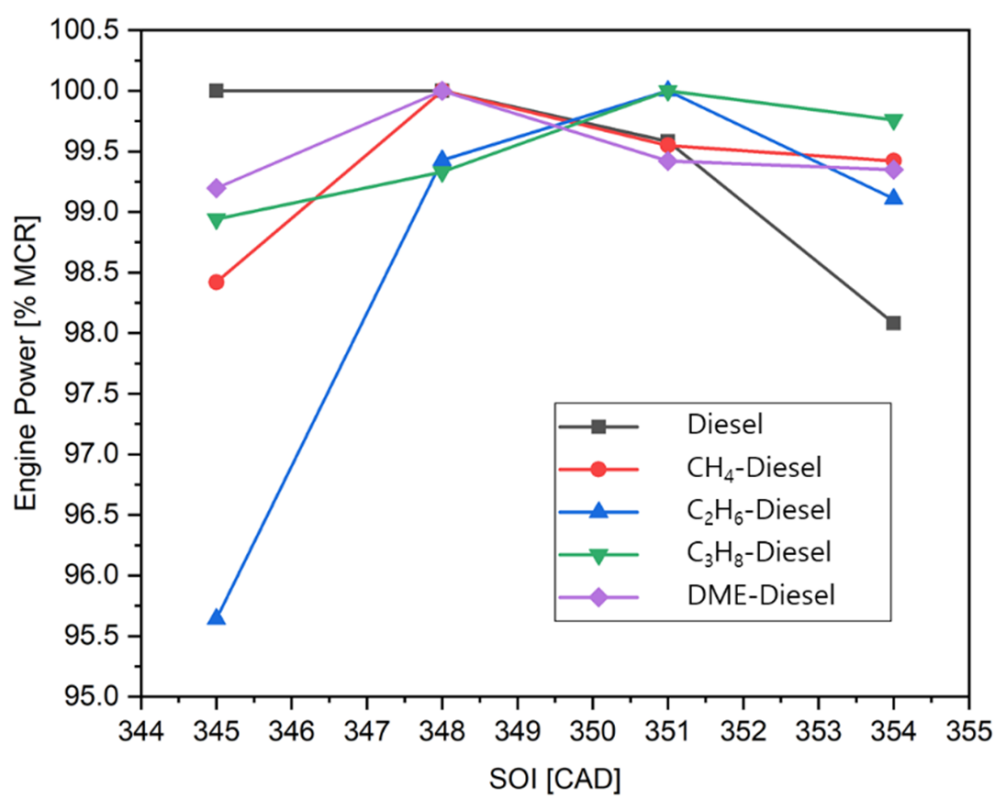

Figure 26. Synthetic of engine power according to pilot SOI angles in all combustion modes.

\section{Conclusions}

In this study, we numerically investigated the combustion process and emission characteristics of a four-stroke gas-diesel DF marine engine at full load using various gases as the primary fuel and diesel oil as the pilot fuel. Additionally, we also investigated the effects of the SOI angle on the combustion process and NO emission formation inside the engine cylinder.

The major results are summarized as below:

I. The simulation result showed that $\mathrm{NO}$ emissions were reduced by up to more than $74.05 \%$, and especially by $96.225 \%$, when operating the engine in the $\mathrm{CH}_{4}$ - or DMEdiesel DF modes, respectively.

II. The amount of soot generated was also significantly reduced when the engine was operated in the DF mode. In particular, the soot generated in the $\mathrm{C}_{3} \mathrm{H}_{8}$-diesel mode was reduced by up to $82.78 \%$ in comparison to the diesel mode. 
III. The $\mathrm{CO}_{2}$ emissions generated in the DF combustions were significantly reduced compared to those in diesel combustion. In particular, the $\mathrm{CH}_{4}$-diesel mode reduced $\mathrm{CO}_{2}$ emission generated up to $21.33 \%$ in comparison to the diesel mode.

IV. The results also showed longer ignition delay times of the combustion processes when the engine was operated in the DF modes.

V. Regarding the effects of the SOI angle on combustion, the results showed reduction tendencies in the in-cylinder peak pressure and temperature as the SOI angle decreased in most cases of combustion. After considering both engine power and $\mathrm{NO}$ emission performance, we recommend the operators should operate the engine with an SOI angle of $351 \mathrm{CAD}$ to get better $\mathrm{NO}$ emission performance while keeping the engine output mostly unchanged.

VI. Applying the SOI angle adjustment method to address an emission problem may lead to an increase in other emissions or a reduction in engine power. Therefore, operators must consider the beneficial aspects and the main target that needs to be achieved, as well as the downside of adopting an SOI angle adjustment strategy to address a certain engine emission problem.

This study successfully analyzed the benefits of using various gas fuels as alternative fuels and the SOI angle adjustment method in DF marine engines to meet the IMO emission regulations without the use of any emission after-treatment devices that were very rare to be found in previous studies. In addition, this study would be a prerequisite for further research on other state-of-the-art dual fuels, such as the methane-hydrogen mixture or ammonia as the primary fuel.

Author Contributions: Conceptualization, V.C.P. and J.-H.C.; Methodology, V.C.P. and W.-J.L.; Software, V.C.P. and B.-S.R.; Validation, V.C.P. and J.-H.C.; Formal analysis, J.-S.K.; Data curation, B.-S.R. and W.-J.L.; Writing-original draft preparation, V.C.P. Writing-review and editing, V.C.P. and J.-H.C.; Project administration, J.-H.C.; Funding acquisition, J.-H.C. All authors have read and agreed to the published version of the manuscript.

Funding: This research was supported by the Ministry of Education of Republic of Korea and the National Research Foundation of Korea (NRF-2019R1G1A1005342).

Institutional Review Board Statement: Not applicable.

Informed Consent Statement: Not applicable.

Data Availability Statement: Not applicable.

Conflicts of Interest: The authors declare no conflict of interest.

\section{References}

1. Geng, P.; Tan, Q.; Zhang, C.; Wei, L.; He, X.; Cao, E.; Jiang, K. Experimental investigation on NOx and green-house gas emissions from a marine auxiliary diesel engine using ultralow sulfur light fuel. Sci. Total. Environ. 2016, 572, 467-475. [CrossRef]

2. Zhang, G.; Yan, H.; Li, T.; Zhu, Y.; Zhou, S.; Feng, Y.; Zhou, W. Relation analysis on emission control and economic cost of SCR system for marine diesels. Sci. Total. Environ. 2021, 788, 147856. [CrossRef]

3. Chu-Van, T.; Ristovski, Z.; Pourkhesalian, A.M.; Rainey, T.; Garaniya, V.; Abbassi, R.; Jahangiri, S.; Enshaei, H.; Kam, U.-S.; Kimball, R.; et al. On-board measurements of particle and gaseous emissions from alarge cargo vessel at different operating conditions. Environ. Pollut. 2018, 237, 832-841. [CrossRef] [PubMed]

4. Thomson, H.; Corbett, J.J.; Winebrake, J.J. Natural gas as a marine fuel. Energy Policy 2015, 87, 153-167. [CrossRef]

5. Wang, Z.; Zhou, S.; Feng, Y.; Zhu, Y. EGR modeling and fuzzy evaluation of Low-Speed Two-Stroke marine diesel engines. Sci. Total. Environ. 2020, 706, 135444. [CrossRef] [PubMed]

6. Bilgili, L. Life cycle comparison of marine fuels for IMO 2020 Sulphur Cap. Sci. Total. Environ. 2021, 774, 145719. [CrossRef] [PubMed]

7. Woodyard, D. Pounders Marine Diesel Engines and Gas Turbines, 9th ed.; Elsevier: Burlington, MA, USA, 2009.

8. Ianniello, R.; Blasio, G.D.; Marialto, R.; Beatrice, C.; Cardone, M. Assessment of direct injected liquefied petroleum gas-diesel blends for ultra-low soot combustion engine application. Appl. Sci. 2020, 10, 4949. [CrossRef]

9. Shamun, S.; Belgiorno, G.; Blasio, G.D.; Beatrice, C.; Tuner, M.; Tunestal, P. Performance and emissions of diesel-biodiesel-ethanol blends in a light duty compression ignition engine. Appl. Therm. Eng. 2018, 145, 444-452. [CrossRef] 
10. Deng, J.; Wang, X.; Wei, Z.; Wang, L.; Wang, C.; Chen, Z. A review of NOx and SOx emission reduction technologies for marine diesel engines and the potential evaluation of liquefied natural gas fueled vessels. Sci. Total. Environ. 2021, 766, 144319. [CrossRef]

11. Peng, W.; Yang, J.; Corbin, J.; Trivanovic, U.; Lobo, P.; Kirchen, P.; Rogak, S.; Gagne, S.; Miller, J.W.; Cocker, D. Comprehensive analysis of the air quality impacts of switching a marine vessel from diesel fuel to natural gas. Environ. Pollut. 2020, 266, 115404. [CrossRef]

12. Yang, C.J.; Leveen, L.; King, K. Ethane as a cleaner Transportation Fuel. Environ. Sci. Technol. 2015, 49, 3263-3264. [CrossRef] [PubMed]

13. Kaiser, E.W.; Siegl, W.O.; Henig, Y.I.; Anderson, R.W.; Trinker, F.H. Effect of fuel structure on emissions from a spark-ignited engine. Environ. Sci. Technol. 1991, 25, 2006-2012. [CrossRef]

14. Kanna, I.V.; Arulprakasajothi, M.; Eliyas, S. A detailed study of IC engines and a novel discussion with comprehensive view of alternative fuels used in petrol and diesel engines. Int. J. Ambient. Energy 2019. [CrossRef]

15. The Word LPG Association (WLPGA). LPG for Marine Engines. The Marine Alternative Fuel; WLPGA: Dublin, Ireland, $2017 ;$ p. 16.

16. Huang, Y.; Sung, C.J. Effects of n-butane addition on reformer gas combustion: Implications for potential of using reformer gas for an engine cold start. Proc. Combust. Inst. 2002, 29, 759-765. [CrossRef]

17. Huang, J.; Wang, Y.; Li, S.; Roskilly, A.P.; Yu, H.; Li, H. Experimental investigation on the performance and emissions of a diesel engine fueled with ethanol-diesel blends. Appl. Therm. Eng. 2009, 29, 2484-2490. [CrossRef]

18. Lee, S.; Oh, S.; Choi, Y.; Kang, K. Performance and emission characteristics of a CI engine operated with n-butane blended DME fuel. Appl. Therm. Eng. 2011, 31, 1929-1935. [CrossRef]

19. Yamasaki, Y.; Iida, N. Numerical analysis of auto-ignition and combustion of n-butane and air mixture in HCCI engine using elementary reactions. JSME Int. J. Ser. B 2003, 46, 52-59. [CrossRef]

20. Saez, A.; Flores-Maradiaga, A.; Toledo, M. Liquid butane as an alternative fuel for diesel oil burners. Appl. Therm. Eng. 2012, 45, 1-8. [CrossRef]

21. Babkin, V.S. Filtrational combustion of gases, present state of affairs and prospects. Pure Appl. Chem. 1993, 65, 335-344. [CrossRef]

22. Fleisch, T.H.; Sills, R.A.; Briscoe, M.D. Emergence of the gas-to-liquid industry: A review of global GTL developments. J. Nat. Gas Chem. 2002, 11, 1-14.

23. Florentius, A.; Hamelinck, C.; Van den Bos, A.; Winkel, R.; Cuijpers, M. Potential of Biofuels for Shipping. Final Report; European Maritime Safety Agency (EMSA): Lisbon, Portugal, 2012.

24. Yoon, D.H.; Yoon, S.H.; Choi, J.H. Experimental study on soot formation in opposed-flow ethylene diffusion flames by mixing dme as an alternative fuel. Korean Soc. Mar. Environ. Saf. 2010, 16, 301-306.

25. Semelsberger, T.A.; Borup, R.L.; Greene, H.L. Dimethyl ether (DME) as an alternative fuel. J. Power Sources 2006, 156, 497-511. [CrossRef]

26. Maurya, R.K.; Mishra, P. Parametric investigation on combustion and emissions characteristics of a dual fuel (natural gas port injection and diesel pilot injection) engine using 0-D SRM and 3D CFD approach. Fuel 2017, 210, 900-913. [CrossRef]

27. Xiang, L.; Song, E.; Ding, Y. A two-zone combustion model for knocking prediction of marine natural gas SI engines. Energies 2018, 11, 561. [CrossRef]

28. Martin, G.C.; Mueller, C.J.; Milam, D.M.; Radovanovic, M.S.; Gehrke, C.R. Early direct-injection, low-temperature combustion of diesel fuel in an optical engine utilizing a 15-hole, dual-row, narrow-included-angle nozzle. SAE Int. J. Engines 2008, 1, 1057-1082 [CrossRef]

29. Polonowski, C.J.; Mueller, C.J.; Gehrke, C.R.; Bazyn, T.; Martin, C.M.; Lillo, M. An experimental investigation of low-soot and soot-free combustion strategies in a heavy-duty, single-cylinder, direct-injection, optical diesel engine. SAE Int. J. Fuels Lubr. 2012, 5, 51-77. [CrossRef]

30. Dunn-Rankin, D. Lean Combustion Technology and Control; Elsevier Ltd.: Amsterdam, The Netherlands; Academic Press: Boston, MA, USA, 2011.

31. Belgiorno, G.; Boscolo, A.; Dileo, G.; Numidi, F.; Pesce, F.C.; Vassallo, A.; Ianniello, R.; Beatrice, C.; Blasio, G.D. Experimental Study of Additive-Manufacturing-Enabled Innovative Diesel Combustion Bowl Features for Achieving Ultra-Low Emissions and High Efficiency. SAE Int. J. Adv. Curr. Pract. Mobil.-V130-99EJ 2021, 3, 672-684. [CrossRef]

32. Dimitrakopoulos, N.; Belgiorno, G.; Tunner, M.; Tunestal, P.; Blasio, G.D. Effect of EGR routing on efficiency and emissions of a PPC engine. Appl. Therm. Eng. 2019, 152, 742-750. [CrossRef]

33. Beatrice, C.; Denbratt, I.; Blasio, G.D.; Luca, G.D.; Ianniello, R.; Saccullo, M. Experimental assessment on exploiting low carbon ethanol fuel in a light-duty dual-fuel compression ignition engine. Appl. Sci. 2020, 10, 7182. [CrossRef]

34. Karim, G.A. Dual-Fuel Diesel Engines; CRC Press: Boca Raton, FL, USA, 2015; pp. 1-312. [CrossRef]

35. Srinivasan, K.K.; Agarwal, A.K.; Krishnan, S.R.; Mulone, V. Natural Gas Engines: For Transportation and Power Generation; Springer: New York, NY, USA, 2018. [CrossRef]

36. Wei, L.; Geng, P. A review on natural gas/diesel dual fuel combustion, emissions and performance. Fuel Process Technol. 2016, 142, 264-278. [CrossRef]

37. Heywood, J.B. Internal Combustion Engine Fundamentals; McGraw-Hill Education: New York, NY, USA, 1998.

38. Turns, S.R. An Introduction to Combustion: Concepts and Applications; McGraw-Hill Education: New York, NY, USA, 2013.

39. Mansurov, Z.A. Soot formation in combustion processes (review). Combust. Explos. Shock. Waves 2005, 41, 727-744. [CrossRef] 
40. Akihama, K.; Takatori, Y.; Inagaki, K.; Sasaki, S.; Dean, A.M. Mechanism of the smokeless rich diesel combustion by reducing temperature. SAE Tech. Pap. Ser. 2001, 110, 648-662. [CrossRef]

41. Neely, G.D.; Sasaki, S.; Huang, Y.; Leet, J.A.; Stewart, D.W. New diesel emission control strategy to meet US Tier 2 emissions regulations. SAE Tech. Pap. Ser. 2005, 114, 512-524. [CrossRef]

42. Caton, J.A. The thermodynamic characteristics of high efficiency, internal-combustion engines. Energy Convers. Manag. 2012, 58, 84-93. [CrossRef]

43. Ma, J.; Lü, X.; Ji, L.; Huang, Z. An experimental study of HCCI-DI combustion and emissions in a diesel engine with dual fuel. Int. J. Therm. Sci. 2008, 47, 1235-1242. [CrossRef]

44. Leermakers, C.; Luijten, C.; Somers, L.; Kalghatgi, G.; Albrecht, B. Experimental study of fuel composition impact on PCCI combustion in a heavy-duty diesel engine. SAE Tech. Pap. Ser. 2011. [CrossRef]

45. Kokjohn, S.L.; Hanson, R.M.; Splitter, D.A.; Reitz, R.D. Fuel reactivity controlled compression ignition (RCCI): A pathway to controlled high-efficiency clean combustion. Int. J. Engine Res. 2011, 12, 209-226. [CrossRef]

46. Splitter, D.; Wissink, M.; Delvescovo, D.; Reitz, R.D. RCCI engine operation towards 60\% thermal efficiency. SAE Tech. Pap. Ser. 2013, 01, 0279. [CrossRef]

47. Korakianitis, T.; Namasivayam, A.M.; Crookes, R.J. Natural-gas fueled spark-ignition (SI) and compression-ignition (CI) engine performance and emissions. Progress Energy Combust Sci. 2011, 37, 89-112. [CrossRef]

48. Belgiono, G.; Blasio, G.D.; Beatrice, C. Parametric study and optimization of the main engine calibration parameters and compression ratio of a methane-diesel dual fuel engine. Fuel 2018, 222, 821-840. [CrossRef]

49. Eder, L.; Ban, M.; Pirker, G.; Vujanovic, M.; Priesching, P.; Wimmer, A. development and validation of 3D-CFD injection and combustion models for dual fuel combustion in diesel ignited large gas engines. Energies 2018, 11, 643. [CrossRef]

50. Pham, V.C.; Choi, J.H.; Rho, B.S.; Kim, J.S.; Park, K.N.; Park, S.K.; Le, V.V.; Lee, W.J. A numerical study on the combustion process and emission characteristics of a natural gas-diesel dual-fuel marine engine at full load. Energies 2021, 14, 1342. [CrossRef]

51. Durbin, P.A. Near-wall turbulence closure modeling without "damping functions". Theor. Comput. Fluid Dyn. 1991, 3, 1-13.

52. Candel, S.; Veynante, D.; Lacas, F.; Maistret, E.; Darabiha, N.; Poinsot, T. Coherent flamelet model: Applications and current extensions. Recent Adv. Combust. Model 1990, 19-64. [CrossRef]

53. AVL FIRE ${ }^{\circledR}$ R2018a. Combustion Module User Manual; AVL List GmbH: Graz, Austria, 2018.

54. Yousefi, A.; Guo, H.; Birouk, M. An experimental and numerical study on diesel ignition split of a natural gas/diesel dual-fuel engine at a low engine load. Fuel 2018, 212, 332-346. [CrossRef]

55. Shu, J.; Fu, J.; Liu, J.; Zhang, L.; Zhao, Z. Experimental and computational study on the effects of injection timing on thermodynamics, combustion and emission characteristics of a natural gas (NG)-diesel dual fuel engine at low speed and low load. Energy Convers. Manag. 2018, 160, 426-438. [CrossRef]

56. Shu, J.; Fu, J.; Liu, J.; Ma, Y.; Wang, S.; Deng, B.; Zeng, D. Effects of injector spray angle on combustion and emissions characteristics of a natural gas (NG)-diesel dual fuel engine based on CFD coupled with reduced chemical kinetic model. Appl. Energy 2019, 182-195. [CrossRef]

57. Ding, C.; Liu, W. Numerical simulation of emission characteristics for single-cylinder diesel engine. Energy Power Eng. 2016, 8, 92-98. [CrossRef]

58. $\quad$ AVL FIRE ${ }^{\circledR}$ R2018a. Spray Module User Manual; AVL List GmbH: Graz, Austria, 2018.

59. Beale, J.C.; Reitz, R.D. Modeling spray atomization with the kelvin-helmotz/Rayleigh-taylor hybrid model. At. Sprays 1999, 9 , 623-650. [CrossRef]

60. $\quad$ AVL FIRE ${ }^{\circledR}$ R2018a. Emission Module User Manual; AVL List GmbH: Graz, Austria, 2018.

61. Raine, R.; Stone, C.; Gould, J. Modeling of nitric oxide formation in spark ignition engines with a multi-zone burned gas. Combust. Flame 1995, 102, 241-255. [CrossRef]

62. Jabbr, A.I.; Vaz, W.S.; Khairallah, H.A.; Koylu, U.O. Multi-objective optimization of operating parameters for hydrogen-fueled spark-ignition engines. Int. J. Hydrog. Energy 2016, 41, 18291-18299. [CrossRef]

63. Scappin, F.; Stefansson, S.H.; Haglind, F.; Andreasen, A.; Larsen, U. Validation of a zero-dimensional model for prediction of NOx and engine performance for electronically controlled marine two-stroke diesel engines. Appl. Therm. Eng. 2012, 37, 344-352. [CrossRef]

64. Naber, J.; Reitz, R.D. Modeling engine spray/wall impingement. SAE Tech. Pap. Ser. 1988, 97, 118-140. [CrossRef]

65. Savli, M. Turbulence Kinetic Energy-TKE; Faculty of Mathematics and Physics, University of Ljubljana: Ljubljana, Slovenia, 2012; Volume 9.

66. Monsalve-Serrano, J.; Belgiorno, G.; Blasio, G.D.; Guzmán-Mendoza, M. 1D simulation and experimental analysis on the effects of the injection parameters in methane-diesel dual-fuel combustion. Energies 2020, 13, 3734. [CrossRef]

67. Polk, A.C.; Carpenter, C.D.; Srinivasan, K.K.; Krishnan, S.R. An investigation of diesel-ignited propane dual fuel combustion in a heavy-duty diesel engine. Fuel 2014, 132, 135-148. [CrossRef]

68. Zhang, Q.; Li, M.; Shao, S. Combustion process and emissions of a heavy-duty engine fueled with directly injected natural gas and pilot diesel. Appl. Energy 2015, 157, 217-228. [CrossRef]

69. Sahoo, B.; Sahoo, N.; Saha, U. Effect of engine parameters and type of gas fuel on the performance of dual-fuel gas diesel engines-A critical review. Renew. Sustain. Energy Rev. 2009, 13, 1151-1184. [CrossRef]

70. Kuo, K.K. Principles of Combustion, 2nd ed.; John Wiley and Sons: New York, NY, USA, 2005. 
71. Fraioli, V.; Beatrice, C.; Blasio, G.D. Multidimensional simulations of combustion in methane-diesel dual-fuel light-duty engines. SAE Tech. Pap. 2017. [CrossRef]

72. Maricq, M.M.; Chase, R.E.; Xu, N.; Laing, P.M. The effects of the catalytic converter and fuel sulfur level on motor vehicle particulate matter emissions: Light duty diesel vehicles. Environ. Sci. Technol. 2002, 36, 283-289. [CrossRef]

73. Burnett, R.T.; Cakmak, S.; Brook, J.R.; Krewski, D. The role of particulate size and chemistry in the association between summertime ambient air pollution and hospitalization for cardiorespiratory diseases. Environ. Health Perspect. 1997, 105, 614-620. [CrossRef]

74. Kittelson, D.; Watts, W.; Johnson, J. On-road and laboratory evaluation of combustion aerosols—Part1: Summary of diesel engine results. J. Aerosol Sci. 2006, 37, 913-930. [CrossRef]

75. Rounce, P.; Tsolakis, A.; York, A.P.E. Speciation of particulate matter and hydrocarbon emissions from biodiesel combustion and its reduction by after-treatment. Fuel 2012, 96, 90-99. [CrossRef]

76. Hura, H.S.; Glassman, I. Fuel oxygen effects on soot formation in counter-flow diffusion flames. Combust. Sci. Technol. 2007, 53, 1-21. [CrossRef]

77. Choi, J.H.; Hwang, C.H.; Choi, S.K.; Lee, S.M.; Lee, W.J.; Jang, S.H.; Park, S.H. Impacts of hydrogen addition on micro and nanostructure of soot particles formed in $\mathrm{C}_{2} \mathrm{H}_{4}$ /air counter diffusion flames. Int. J. Hydrog. Energy 2016, 41, 15852-15858. [CrossRef]

78. Valder Wal, R.L.; Jensen, K.A.; Choi, M.Y. Simultaneous laser-induced emission of soot and polycyclic aromatic hydrocarbons within a gas-jet diffusion flame. Combust. Flame 1997, 109, 399-414. [CrossRef]

79. Yoon, S.S.; Lee, S.M.; Chung, S.H. Effect of mixing methane, ethane, propane, and propene on the synergistic effect of PAH and soot formation in ethylene-base counter-flow diffusion flames. Proc. Combust. Inst. 2005, 30, 1417-1424. [CrossRef]

80. Choi, J.H. Experimental study on characteristics of synergistic effect of fuel mixing on number density and size of soot in ethylene-base counter-flow diffusion flames by laser techniques. J. Korean Soc. Mar. Eng. 2009, 33, 378-386. [CrossRef]

81. Choi, B.C.; Choi, S.K.; Chung, S.H.; Kim, J.S.; Choi, J.H. Experimental and numerical investigation of fuel mixing effects on soot structure in counter-flow diffusion flames. Int. J. Automot. Technol. 2011, 12, 183-191. [CrossRef]

82. Laidler, K.J.; Wojciechowski, B.W. Kinetic and mechanisms of the thermal decomposition of ethane. i. the uninhibited reaction. Proceeding R. Soc. A 1961, 260, 91-102. [CrossRef]

83. Palmer, H.B.; Lahaye, J.; Hou, K.C. On the kinetics and mechanism of the thermal decomposition of methane in a flow system. J. Phys. Chem. 1968, 72, 348-353. [CrossRef]

84. Lifahitz, A.; Frenklach, M. Mechanism of the high temperature decomposition of propane. J. Phys. Chem. 1975, 79, 686-692. [CrossRef]

85. Oehlschlaeger, M.A.; Davidson, D.F.; Hanson, R.K. High-temperature thermal decomposition of isobutane and n-butane behind shock waves. J. Phys. Chem. 2004, 108, 4247-4253. [CrossRef] 